\title{
Numerical Simulation of the Failure Propagation of Masonry Buildings during an Earthquake
}

\author{
Aiko FuRUKAWA* \\ Junji KIYONO** \\ Kenzo ToKI*** \\ *Assistant Professor, Civil and Earth Resources Engineering, Kyoto University \\ **Professor, Department of Urban Management, Kyoto University \\ ***Professor, Disaster Mitigation of Urban Cultural Heritage, Ritsumeikan University
}

(Received December 2, 2010 Accepted October 4, 2011)

\begin{abstract}
The process of failure propagation of masonry buildings during earthquakes is simulated using a refined version of the distinct element method that simulates three-dimensional elastic, failure, and collapse behaviors of structures. Models with a flat roof and models with a vault roof are considered, and their failure propagation mechanisms are examined. The influence of the direction of the input ground motion on failure propagation is also investigated. Moreover, the effectiveness of three reinforcement measures is compared. One measure is increasing the mortar strength, the second is increasing the thickness of the bearing walls, and the third is introducing wooden columns and beams. Among these measures, increasing the mortar strength is found to be the most effective. Increasing the thickness of the bearing walls and introducing wooden columns and beams are found to be effective only if the roof has sufficient integrity since the collapse of the roof depends on the integrity of the bearing walls and the roof itself.
\end{abstract}

Keyword: failure propagation process; masonry building; earthquake; distinct element method

\section{Introduction}

The principal cause of death due to earthquakes is the collapse of buildings, which has accounted for $75 \%$ of earthquake fatalities over the last century [1]. In particular, the collapse of masonry buildings has killed a large number of victims [2]. An adobe building is a masonry structure made of sun-dried bricks (adobe bricks) and mortar and has particularly low earthquake resistance. Such structures collapse even at low intensities of ground motion and collapse rapidly at high intensities. EMS98 is a macroseismic scale pro- posed by the European Seismological Commission in 1998, which was modified from the MSK scale (1964) to be applicable to various modern structures [3]. Similar to the MSK scale, EMS98 categorizes the vulnerability classes of buildings from $\mathrm{A}$ to $\mathrm{F}$, and adobe buildings are classified as vulnerability class $\mathrm{A}$, which is the weakest type of building. EMS98 also classifies damage to buildings into five grades from G1 to G5 (G1: negligible to slight damage, G2: moderate damage, G3: substantial to heavy damage, G4: very heavy damage, G5: destruction). The relationship between the damage grade of adobe buildings and the EMS98 
intensity is defined as follows. At intensity $\mathrm{V}$, a few (0-20\%) buildings have grade G1 damage. At intensity VI, a few adobe buildings have grade G2 damage and many (20-60\%) have grade G1 damage. At intensity VII, a few adobe buildings have grade G4 damage and many have grade G3 damage. At intensity VIII, a few adobe buildings have grade G5 damage and many have grade G4 damage. At intensity IX, the damage to many adobe buildings is grade G5, and at intensity $\mathrm{X}$, the damage to most (60-100\%) adobe buildings is grade G5.

Therefore, it is necessary to improve the earthquake resistance of these primarily weak masonry buildings to reduce the number of casualties. However, knowledge is still limited as to how the failure begins and proceeds, how buildings collapse, and how earthquake resistance can effectively be improved. With this background, a series of seismic behaviors - from elastic to failure to collapse behaviors-is simulated using a refined version of the distinct element method [4].

Among numerical simulation methods, the finite element method (FEM) is the most common for the analysis of a continuum [5]. It can deal with both elastic and plastic behaviors, but it has difficulty in solving failure and collapse phenomena since it is based on the mechanics of the continuum and uses a continuous shape function. Ghannad et al. [6] conducted seismic simulation of typical Iranian masonry buildings using the FEM, and assessed the initiation of cracks from stress distributions. The crack pattern obtained by the analysis was in good agreement with actual crack occurrence during the Bam earthquake. Cao et al. [7] computed the earthquake response of adobe structures with a joint element that expresses the separation and sliding between bricks. Gambarotta and Lagomarsino [8] and Lourenco et al. [9] introduced joint elements at the interface as well as inside each brick, and simulated cracks inside the bricks. They confirmed the validity of their simulation by comparing the simulation results with the experimental results. In this way, the FEM can simulate discontinuous phenomena such as cracking, separation, and sliding through the use of joint elements. It is still difficult, however, to simulate total collapse behavior employing the FEM.
A method based on discontinuum modeling is more suitable for analyzing failure and collapse phenomena. Examples of numerical methods for a discontinuum are the distinct element method (DEM) [10], discontinuous deformation analysis (DDA) [11], and the rigid-body spring method (RBSM) [12]. However, these methods have disadvantages. In the DEM, a way of determining the spring constant from the material properties has not been established, and the values need to be quantified experimentally. Therefore, the reliability of the results is not high. For example, Alexandris et al. [13] adopted the DEM to investigate the crack patterns and collapse mechanism of stone masonry structures subjected to severe earthquake excitations. They calibrated the analytical parameters by comparing the numerical prediction of the response with experimental results. The calibrated parameters depend on the scale of the structures, so they do not always give a reliable solution if the calibrated parameters are applied to models of different scale. The disadvantage of DDA is that the formulation is complicated since inequality equations need to be solved. Therefore, application to a three-dimensional problem is considered difficult even though it is possible in theory. The RBSM is not suitable for large displacement problems since it does not consider the recontact of an element with neighboring elements other than the element with which contact is initially set.

As an alternative, the present paper uses a refined version of distinct element method, which simulates three-dimensional elastic, failure, and collapse behaviors [4]. The method models the structure as an assembly of rigid elements and cannot handle Poisson's effect like the DEM, but unlike the DEM, interaction between elements is modeled by multiple springs and multiple dashpots attached to the surfaces of the elements. The spring constant of each spring is theoretically determinable.

Using this method, this study simulates the seismic behavior of simplified adobe buildings in Iran. Models with a flat roof and models with a vault roof are considered, and their failure propagation mechanisms are examined and compared. The influence of the direction of the input ground motion on the process of failure propagation is also investigated. The outcomes of the simulation are compared with examples from past 
earthquakes to confirm the reliability of the simulation. Moreover, this study investigates the effectiveness of reinforcement measures. Through a damage survey, it is pointed out that poor-quality mortar, weak wall-towall connection, and lack of out-of-plane resistance of walls are important issues in considering the seismic vulnerability of rural houses in Iran [14]. Therefore, this study considers three reinforcement measures. One is increasing the mortar strength, which increases brick-to-brick connections and wall-to-wall connections as a result. The second is increasing the thickness of the bearing walls, which increases their out-of-plane resistance. The third is introducing wooden columns and beams, which increases the out-of-plane resistance of walls and wall-to-wall connections. The effects of roof type, direction of ground motion, and reinforcement measures on failure propagation are investigated in terms of tensile cracking, building deformation, and scattering of bricks determined by simulation.

\section{Analytical Method}

\subsection{Basic concept}

This study employs a refined version of the DEM to simulate a series of structural dynamic behaviors from elastic to failure to collapse phenomena. A structure is modeled as an assembly of rigid elements, and interaction between the elements is modeled with multiple springs and multiple dashpots that are attached to the surfaces of the elements. The elements are rigid, but the method allows the simulation of structural deformation by permitting penetration between elements.

Figure 1 (a) shows a spring for computing the restoring force (restoring spring), which models the elasticity of elements. The restoring spring is set between continuous elements. Structural failure is modeled as breakage of the restoring spring, at which time the restoring spring is replaced with a contact spring and a contact dashpot (Fig. 1 (b) ). Figure 1 (b) shows the spring and dashpot for computing the contact force (contact spring and dashpot) and modeling the contact, separation, and recontact between elements. The dashpots are introduced to express energy dissipation due to the contact. Structural collapse behavior is obtained using these springs and dashpots. The elements shown in Figs. 1 (a) and (b) are rectangular parallelepipeds, but the method does not limit the geometry of the elements.
The surface of an element is divided into small segments as shown in Fig. 1 (c). The segment in the figure is rectangular, but the method does not limit the geometry of the segment. The black points indicate the representative point of each segment, and the relative displacement or contact displacement between elements is computed for these points. Such points are referred to as contact points or master points in this study. One restoring spring and one combination of contact spring and dashpot are attached to one segment (Fig. 1 (d) ) at each of the representative points in Fig. 1 (c). The spring constant for each segment is derived on the basis of the stress-strain relationship of the material and the segment area.

Forces acting on each element are obtained by summing the restoring force, contact force, and other external forces such as the gravitational force and inertial force of an earthquake. The behavior of an element consists of the translational behavior of the center of gravity and the rotational behavior around the center of gravity. The translational and rotational behaviors of each element are computed explicitly by solving Newton's law of motion and Euler's equation of motion.

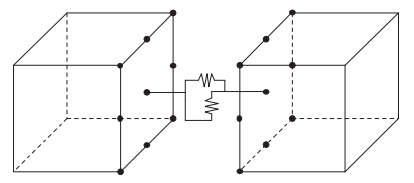

(a) Restoring spring

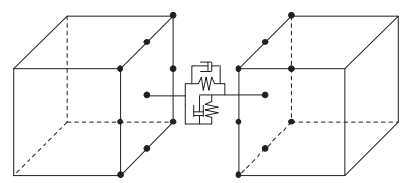

(b) Contact spring and dashpot

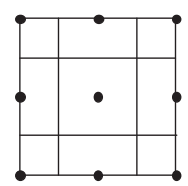

(c) Segments and contact points

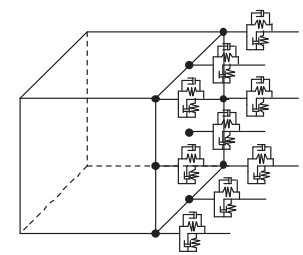

(d) Multiple springs and multiple dashpots

Fig. 1 Basic concept of the analysis method 


\subsection{Spring constant of each element}

As described in Section 2.1, there are two types of springs, namely restoring and contact springs. It is assumed that the spring constants of the restoring spring and those of the contact springs are the same. It is considered that each segment has its own spring.

Springs are set for both the normal and shear (tangential) directions of the surface. Let us denote the area of the segment as $d A$ and the relative (contact) displacement at the surface segment as $u_{n}$ and $u_{s}$. The subscripts $n$ an $s$ indicate the values in the normal and shear directions, respectively. The spring constants per area in the normal and shear directions, $k_{n}$ and $k_{s}$, are obtained as follows [4].

$$
k_{n}=\frac{E}{\left(1-v^{2}\right) \ell}, \quad k_{s}=\frac{E}{2(1+v) \ell},
$$

where $E$ is Young's modulus, $v$ is Poisson's ratio, and $\ell$ is the distance from the surface at which the spring is connected to the center of gravity.

\subsection{Modeling of elastic behavior}

It is assumed that two elements, $A$ and $B$, are continuous, and that a contact point of element $A$ is continuous with element $B$ as shown in Fig. 2 (a). The contact point of element $A$ is the "master point" and the contact point of element $B$ is the "slave point." The slave point does not have to be the center of the segment. The combinations of continuous elements for each segment are determined in the initial stage of the computation.

Let $G_{A}$ and $G_{B}$ be the centers of gravity of elements $A$ and $B$, respectively. Let $\ell_{A}$ be the distance from $G_{A}$ to the surface of element $A$ in contact. Let $\ell_{B}$ be the distance from $G_{B}$ to the surface of element $B$ in contact. Let $E_{A}$ and $E_{B}$ be Young's moduli and $v_{A}$ and $v_{B}$ be Poisson's ratios of elements $A$ and $B$.

It is assumed that both elements have their own spring constants in the normal and shear directions based on their material properties as shown in Fig. 1 (b). The spring constants per area for each element are obtained from Eq. (1). Assuming that these springs are connected in series, the spring constants between elements per area, $\bar{k}_{n}$ and $\bar{k}_{s}$, are shown in Fig. 2 (b).

$$
\begin{gathered}
\bar{k}_{n}=\frac{1}{\frac{\ell_{A}}{E_{A} /\left(1-v_{A}^{2}\right)}+\frac{\ell_{B}}{E_{B} /\left(1-v_{B}^{2}\right)}}, \\
\bar{k}_{s}=\frac{1}{\frac{\ell_{A}}{E_{A} / 2\left(1+v_{A}\right)}+\frac{\ell_{B}}{E_{B} / 2\left(1+v_{B}\right)}} .
\end{gathered}
$$

The spring constant between elements connected by mortar is also obtained in a similar manner. For example, in masonry structures, bricks are often connected with mortar. In this case, the spring constant per area between elements (bricks) is obtained as

$$
\bar{k}_{n}=\frac{1}{\frac{\ell_{A}-t_{M} / 2}{E_{A} /\left(1-v_{A}^{2}\right)}+\frac{t_{M}}{E_{M} /\left(1-v_{M}^{2}\right)}+\frac{\ell_{B}-t_{M} / 2}{E_{B} /\left(1-v_{B}^{2}\right)}},
$$

$$
\bar{k}_{s}=\frac{1}{\frac{\ell_{A}-t_{M} / 2}{E_{A} / 2\left(1+v_{A}\right)}+\frac{t_{M}}{E_{M} / 2\left(1+v_{M}\right)}+\frac{\ell_{B}-t_{M} / 2}{E_{B} / 2\left(1+v_{B}\right)}},
$$

where $t_{M}$ is the mortar thickness, $E_{M}$ is Young's modulus, and $v_{M}$ is Poisson's ratio of the mortar. The normal direction of forces is the direction perpendicular to the surface of the master point of element $A$.

Let $\sigma$ and $\tau$ be the normal and shear stresses acting at the contact point, and let $u_{n}$ and $u_{s}$ be the relative displacements between the adjacent master and slave points in the normal and shear directions. The relation between traction $(\sigma, \tau)$ and relative displacement $\left(u_{n}\right.$, $\left.u_{s}\right)$ is then written as

$$
\sigma=\bar{k}_{n} u_{n}, \quad \tau=\bar{k}_{s} u_{s} .
$$

It is noted that the method cannot handle Poisson's effect since it considers the contact between two elements.

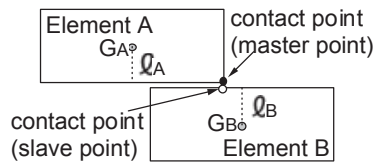

(a) Continuous elements

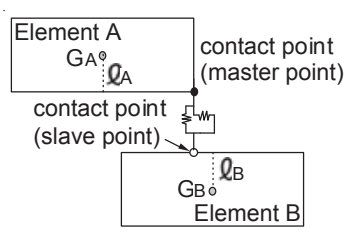

(b) Restoring spring between elements
Fig. 2 Modeling of the restoring spring between elements 


\subsection{Modeling of failure phenomena}

The elastic behavior of structures is demonstrated by the linear multiple restoring springs between continuous elements until the restoring force of a spring reaches its elastic limit. The elastic limits are modeled using the criteria of tension, shear, and compression failure. When a spring reaches one of these limits, it is judged that failure has occurred at that segment of the spring. After the failure, the restoring spring is replaced with a contact spring and dashpot at this segment. The method can trace the expansion of failure between elements. The three failure modes - namely, tension, shear, and compression failure modes - are defined based on the Mohr-Coulomb cap model as follows.

\section{(1) Tension failure mode}

For the tension failure mode, the parameter considered is tensile strength $f_{t}$. When the normal stress of spring $\sigma$ exceeds the tensile strength, the restoring spring is assumed to be broken by the tension failure. The yield function has the following form (Fig. 3).

$$
f_{1}(\sigma)=\sigma-f_{t}
$$

The normal restoring stress cannot exceed this limit.

\section{(2) Shear failure mode}

For the shear failure mode, the Coulomb friction envelope is used. The parameters considered are bond strength $c$ and friction angle $\phi$. The yield function has the following form (Fig. 3).

$$
f_{2}(\sigma)=|\tau|+\sigma \tan \phi-c .
$$

The shear restoring stress cannot exceed this limit.

\section{(3) Compression failure mode}

For the compression mode, an ellipsoid cap model is used. The yield function has the following form (Fig. 3).

$$
f_{3}(\sigma)=\sigma^{2}+C_{s} \tau^{2}-f_{m}{ }^{2},
$$

where $f_{m}$ is the compressive strength and $C s$ is the material model parameter. $C s=9$ is adopted on the basis of past research [15]. When the restoring stress exceeds this limit, both the normal and shear restoring stresses are reduced in the same proportion to meet this limit.

In real structures, failure occurs not only at the mortar, but also inside bricks and at the interface between brick and mortar. However, in this study, it is assumed that failure does not occur inside bricks but at the interface between bricks, and we do not discriminate failure at the mortar from failure at the interface between brick and mortar. The restoring spring between elements is linear until any failure occurs. In tension, linear tensile reaction force acts until it reaches the tensile strength. After tensile failure, no tensile reaction force acts between these elements until they are in contact again. In compression, the linear compressive reaction force acts until it reaches the compression strength, and the compressive reaction force then obeys the Mohr-Coulomb cap model. During the unloading process after the failure, the compressive strength decreases linearly with the initial stiffness, and it becomes 0 when elements are separated. The shear reaction force is also linear until it reaches the shear strength, and it then obeys the Mohr-Coulomb cap model. During the unloading process after the failure, the shear strength decreases linearly with the initial stiffness and obeys the limit of Eq. (6). Since the face of the elements is divided into many segments and each segment has its own spring, these springs gradually break during loading.

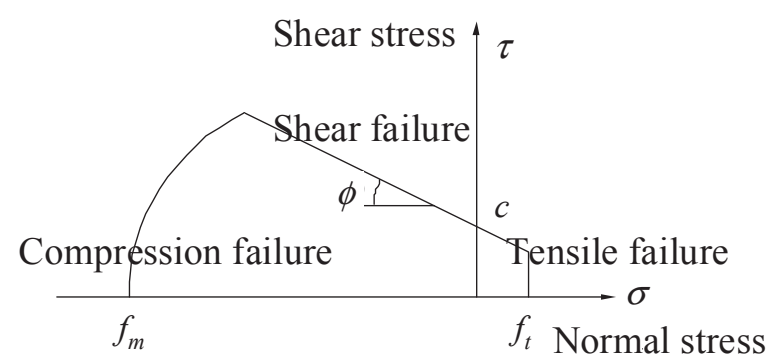

Fig. 3 Modeling of failure phenomena

\subsection{Modeling of contact and recontact between elements}

If a segment of an element is in contact with another element with which the segment is not continuous via the restoring spring, the contact spring and dashpot generate contact force between the elements. Contact between a segment and the surface of another element is detected at each time step for all segments that are not continuous with other elements via a restoring spring.

Figure 4 (a) illustrates the situation where a contact point of element $A$ is in contact with discontinuous element $B$, and Fig. 4 (b) shows the contact spring and dashpots between these elements. 
The spring constant and the contact forces in the normal and shear directions are calculated in the same manner as for the restoring force. The differences from the case for the restoring force are that the contact force is generated only while the compression force acts and that the shear force is bounded by the friction limit.

$$
\tau=\sigma \tan \phi
$$

where $\phi$ is the friction angle.

The dashpot is introduced to express the energy dissipation of the contact. The damping coefficient per area is calculated as follows.

$$
c_{n}=2 h_{n} \sqrt{m_{a v e} k_{n}}, \quad c_{s}=2 h_{s} \sqrt{m_{a v e} k_{s}},
$$

where $h_{n}$ and $h_{s}$ are the damping constants for the normal and shear directions. $m_{\text {ave }}$ is the equivalent mass per area relevant to this contact. In this study, $m_{\text {ave }}$ is calculated as

$$
m_{\text {ave }}=\rho_{A} \ell_{A}+\rho_{B} \ell_{B},
$$

where $\rho_{A}$ and $\rho_{B}$ are the mass densities of elements $A$ and $B$.

The damping constants should be evaluated according to the properties of the elements, but this study adopts critical damping $\left(h_{n}=h_{s}=1.0\right)$ by considering the fact that most structural components tend not to bounce greatly and that their oscillation tends to quickly disappear when they collide with each other.

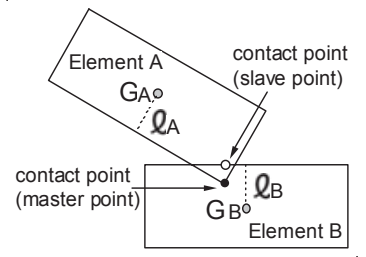

(a) Discontinuous elements in contact

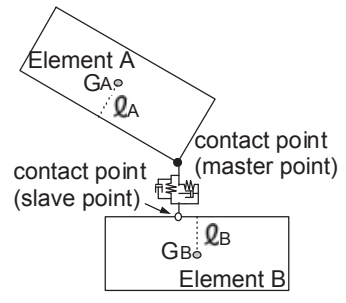

(b) Contact spring and dashpot between elements
Fig. 4 Modeling of the contact spring and dashpot between elements

\subsection{Restoring and contact forces acting at each element}

The restoring and contact forces are calculated at all segments for both elements $A$ and $B$. The restoring and contact forces acting at each point are obtained by considering the area of the master point. Assuming $d A$ is the area of the master point, the effective area can be half the segment area $d A$ to avoid double counting of the contact force, since the contact points of both elements $A$ and $B$ can be the master points. Therefore, assuming that $d A / 2$ is the effective area of the master point, the spring constants and damping coefficients are

$$
\begin{array}{cc}
K_{n}=\bar{k}_{n} d A / 2, & K_{s}=\bar{k}_{s} d A / 2, \\
C_{n}=c_{n} d A / 2, & C_{s}=c_{s} d A / 2 .
\end{array}
$$

In consideration of this, the size of the segments should be small and the same for elements $A$ and $B$. Finally, the spring forces $\left(\mathbf{e}_{\mathbf{n}}, \mathbf{e}_{\mathbf{s}}\right)$ and damping forces $\left(\mathbf{d}_{\mathbf{n}}, \mathbf{d}_{\mathbf{s}}\right)$ in the normal and shear directions are written as

$$
\begin{array}{cc}
\mathbf{e}_{n}=K_{n} \mathbf{u}_{n}, & \mathbf{e}_{s}=K_{s} \mathbf{u}_{s}, \\
\mathbf{d}_{n}=C_{n} \Delta \mathbf{u}_{n} / \Delta t, & \mathbf{d}_{s}=C_{s} \Delta \mathbf{u}_{s} / \Delta t,
\end{array}
$$

where $\Delta \mathbf{u}_{\mathbf{n}}$ and $\Delta \mathbf{u}_{\mathrm{s}}$ are the increments of relative displacement and $\Delta t$ is the time interval. The variables written in bold face are vectors

\subsection{Structural damping}

In this study, structural damping that expresses energy dissipation in structural vibration is considered. This differs from energy dissipation of the contact expressed by damping constants $c_{n}$ and $c_{s}$.

Damping constant $c$ is introduced as mass-proportional damping as

$$
c=\alpha m,
$$

where $\alpha$ is a variable defining the damping constant. $\alpha$ can be calculated as

$$
\alpha=2 h_{i} \omega_{i},
$$

where $\omega_{i}$ is the angular frequency and $h_{i}$ is the corresponding damping constant.

Mass-proportional damping is adopted since the method solves the equation of motion for each element and mass-proportional damping is easily applicable. The dashpot attached between contact elements is a stiffness-proportional damping. We plan to investigate an appropriate model of damping in a future study.

\subsection{Equations of motion}

Equations of motion can be constructed using the restoring and contact forces and other external forces. 
The motion of each element is obtained by solving the two equations of motion. One is the equation for the translational motion of the center of gravity, and the other is the equation for the rotational motion around the center of gravity.

\section{(1) Translational motion of the center of gravity}

The forces acting on an element are the sum of external forces, such as the gravitational force and inertial force due to an earthquake, and the restoring and contact forces between elements. The equation of motion for the translational motion is

$$
m \ddot{\mathbf{x}}_{g}(t)+c \dot{\mathbf{x}}_{g}(t)=m \mathbf{g}-m \ddot{\mathbf{z}}(t)+\sum \mathbf{F}(t),
$$

where $\mathbf{x}_{\mathbf{g}}(t)$ is the displacement vector of the center of gravity of an element at time $t, m$ is the mass of the element, $c$ is the damping constant of the element, $\mathbf{g}$ is the gravitational acceleration vector, $\ddot{\mathbf{z}}_{\mathbf{t}}$ is the ground acceleration vector at time $t$, and $\Sigma \mathbf{F}(t)$ is the sum of the restoring and contact force vectors at time $t$.

\section{(2) Rotational motion around the center of gravity}

First, the angular velocity vector $\omega(t)$ is obtained by solving the following Euler equation of motion.

$$
\mathbf{I} \dot{\boldsymbol{\omega}}(t)+\boldsymbol{\omega}(t) \times \mathbf{I} \boldsymbol{\omega}(t)=\sum \mathbf{R}(t) \mathbf{r}(t) \times \mathbf{R}(t) \mathbf{F}(t) .
$$

Here, $\mathbf{I}$ is the tensor of the moment of inertia, $\mathbf{r}(t)$ is the vector between the center of gravity and the point where force $\mathbf{F}(t)$ is applied. $\mathbf{R}(t)$ is the matrix representing the transformation from the absolute coordinate system to the inertial frame of reference.

The vector from center of gravity $\mathbf{x}_{\mathbf{g}}(t)$ to arbitrary point $\mathbf{x}_{\mathbf{p}}(t)$ in an element, $\mathbf{x}_{\mathbf{g p}}(t)$, is obtained by solving the following differential equation using the angular velocity vector.

$$
\dot{\mathbf{x}}_{g p}(t)=\left(\mathbf{R}^{T}(t) \boldsymbol{\omega}(t)\right) \times \mathbf{x}_{g p}(t),
$$

where $\boldsymbol{\omega}(t)$ is the angular velocity vector in the inertial frame of reference obtained by solving Eq. (16).

The coordinates of point $\mathbf{x}_{\mathbf{p}}(t)$ are then obtained as follows.

$$
\mathbf{x}_{p}(t)=\mathbf{x}_{g}(t)+\mathbf{x}_{g p}(t) .
$$

In this study, Eqs. (15) - (18) are solved explicitly using the central difference scheme.

\subsection{Critical time interval}

Since the equations of motion are solved explicitly, the solution is conditionally stable [16]. The following inequality is used to determine the time interval for the computation.

$$
\Delta t \leq \min \left(\ell / \sqrt{\frac{E /\left(1-v^{2}\right)}{\rho}}\right) .
$$

The term on the right hand side of Eq. (19) is obtained for all segments of all elements, and the time interval is determined. If the solution is unstable using this time step, a smaller value is used until stability is attained.

\section{Analysis Outline}

\subsection{Modeling of bricks and mortar}

In this study, individual components of the masonry structure shown in Fig. 5 (a) (i.e., brick and mortar joints) are modeled in a simple manner as shown in Fig. 5 (b). The bricks are modeled with rigid elements and the mortar joint between elements is modeled with multiple springs and multiple dashpots. The size of one element is the sum of the brick size and the thickness of mortar together. The multiple springs and multiple dashpots interact with the surfaces of adjacent elements.

The modeling in this study is three-dimensional, and the elements are modeled with rigid rectangular parallelepipeds and hexahedrons. Faces surrounding the elements are divided into segments. The interval between contact points of neighboring segments is set to a quarter of the shortest edge length according to a past study [4]. The method was verified through a comparison with the experimental results of monotonic loading and the analytical results of free vibration by the FEM [4]. Verification by comparison with cyclic loading and shaking table tests is very important and comprises one of our future plans. The dynamic failure patterns and scattering of elements, which will be shown later, are numerical solutions based on the assumptions shown in the previous section. Moreover, adobe brick is a very brittle material compared to other masonry elements such as burnt brick, stone, and concrete block, and the adobe bricks themselves fracture during earthquakes. However, due to the limitation of the analytical method, we do not model failure inside such bricks. Therefore, the solution focuses on structures where mortar failure is dominant and brick 
failure is negligible. In this respect, the method may not be appropriate for structures where failure inside the bricks occurs with high probability. Modeling of failure of the brick itself is also one of our future plans.

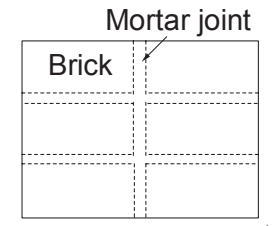

(a) Masonry structure

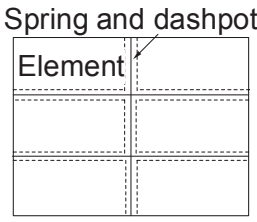

(b) Analytical model
Fig. 5 Analytical modeling of masonry structures

\subsection{Analytical models}

Figure 6 illustrates the two masonry models analyzed in this study. One has a flat roof made of wooden beams, and the other has a vault roof made of adobe bricks. The directions $(x, y, z)$ are also shown in Fig. 6 . In each model, the walls facing the $y$ direction support the roof; therefore, these walls are referred to as bearing walls and the other two walls are referred to as nonbearing walls. The basement is modeled by a fixed element (not shown in the figure) and the model is placed on the basement.

\section{(1) Flat roof model}

The flat roof model has two bearing walls, two nonbearing walls, and a flat roof. The external width of the building is $5.4 \mathrm{~m} \times 3.4 \mathrm{~m}$, and the internal width is $5.0 \mathrm{~m} \times 3.0 \mathrm{~m}$. The height of the walls is $2.4 \mathrm{~m}$. The thickness of walls is $0.2 \mathrm{~m}$. The walls are composed of bricks with dimensions of $0.2 \mathrm{~m} \times 0.1 \mathrm{~cm} \times 0.1$ $\mathrm{m}$. There are mortar joints with a thickness of 0.01 $\mathrm{m}$ between the bricks. Bricks are stacked according to the English bond model. The connections between walls and their perpendicular walls are constructed by mortar and bricks stacked with a shift of half the brick length in alternating layers.

One of the bearing walls has a door opening and a window opening. The size of the door is $1.2 \mathrm{~m}$ (width) $\times 2.0 \mathrm{~m}$ (height). The size of the window is $1.0 \mathrm{~m} \times 1.0$ $\mathrm{m}$, and the height of the lower side of the window is 1.0 $\mathrm{m}$. There are wooden beams above the openings that support the elements above the openings. The dimensions of the beams above the openings are $0.2 \mathrm{~m} \times$ $0.1 \mathrm{~m} \times 1.4 \mathrm{~m}$ (length). These beams are divided into elements of 0.2-m length to express their deformation and separation.

The roof consists of 27 beams that run in the $y$ direction. The dimensions of the beams are $0.2 \mathrm{~m} \times 0.2 \mathrm{~m}$ $\times 3.4 \mathrm{~m}$ (length). These roof beams are also divided into elements of 0.2-m length to express their deformation and separation. The roof beams rest on the walls and there are mortar joints between the beams and walls. Wooden beams are also modeled with rigid elements in the same manner as for the bricks. The conjunction between wooden elements has the strength of wood.

\section{(2) Vault roof model}

The vault roof model has two bearing walls, two nonbearing walls, and a vault roof. Modeling lower than $2.4 \mathrm{~m}$ is the same as that for the flat roof model.

The roof has a semicircular profile with a radius of $1.5 \mathrm{~m}$. The dimensions of the bricks for the walls are basically the same as those of the flat roof model, but if the brick is adjoining the roof, it is then cut to make the wall semicircular. The vault roof has a thickness of $0.2 \mathrm{~m}$ and is divided into bricks having a section area of $0.2 \mathrm{~m} \times 0.2 \mathrm{~m}$ in the radial direction and a length of close to $0.2 \mathrm{~m}$ in the tangential direction.

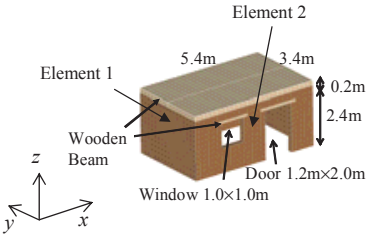

(a) Flat roof model

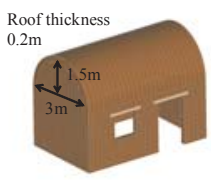

(b) Vault roof model
Fig. 6 Masonry models

\subsection{Analytical cases}

\section{(1) Mortar strength}

Kiyono et al. conducted a field experiment to measure the mortar strength of a damaged adobe building during a reconnaissance survey of the damage resulting from the Bam earthquake in Iran [17]. The results are shown in Table 1 and are referred to as the results for weak mortar in this study.

Ghannand et al. conducted a laboratory experiment to measure the strength of the adobe bricks used in rural regions in Iran [6]. The results are shown in Table 1 
Table 1 Strength of mortar and wood

\begin{tabular}{|c||c|c|c|c|}
\hline Variable & $\begin{array}{c}\text { Weak } \\
\text { mortar [17] }\end{array}$ & $\begin{array}{c}\text { Normal } \\
\text { mortar [6] }\end{array}$ & $\begin{array}{c}\text { Strong } \\
\text { mortar [18] }\end{array}$ & Wood \\
\hline \hline Tensile strength $f_{\mathrm{t}}\left(\mathrm{N} / \mathrm{m}^{2}\right)$ & $4.6 \times 10^{3}$ & $1.27 \times 10^{5}$ & $1.42 \times 10^{6}$ & $1.1 \times 10^{7}$ \\
\hline Shear strength $c\left(\mathrm{~N} / \mathrm{m}^{2}\right)$ & $2.9 \times 10^{3}$ & $3.04 \times 10^{4}$ & $1.19 \times 10^{6}$ & $9.0 \times 10^{6}$ \\
\hline Friction angle $\phi$ & $32^{\circ}$ & $\begin{array}{c}\text { No data } \\
\left(32^{\circ} \text { used }\right)\end{array}$ & $36^{\circ}$ & $0^{\circ}$ \\
\hline Compressive strength $\left(\mathrm{N} / \mathrm{m}^{2}\right)$ & $\begin{array}{c}\text { No data } \\
\left(4.9 \times 10^{5} \text { used }\right)\end{array}$ & $4.9 \times 10^{5}$ & $2.66 \times 10^{7}$ & $4.5 \times 10^{7}$ \\
\hline
\end{tabular}

and are referred to as the results for normal mortar in this study.

Since the compression strength was not measured for weak mortar [17], the value for normal mortar is used. In addition, since the friction angle was not given for normal mortar [6], the value for weak mortar is used. The outcome of the simulation does not depend on these values since all models only suffered tensile failure in this study as explained later.

For comparison, the mortar strength of bricks used in Europe measured by Marzahn is given in Table 1 and is referred to as the strength of strong mortar in this study [18].

The results show that the mortar used in Europe is much stronger than that used in Iran, and that buildings damaged during the Bam earthquake had especially weak mortar strength. It is unrealistic to apply strong mortar to weak adobe bricks, but this case is chosen to investigate the effect of mortar strength.

The variation in the mortar strength of adobe buildings may be large, but this study conducted a deterministic analysis without considering variation in properties. We discuss the effect of mortar strength by simply comparing the results for three different mortar strengths. Failure of the brick itself is ignored considering that the most failure occurs at the mortar conjunction.

Wooden columns and beams are divided into many elements to express deformation and breakage.

The breakage is modeled for the mortar listed in Table 1.

\section{(2) Analytical cases}

Five models are considered for flat and vault roof models as presented by Fig. 7 and Table 2 .

- Flat20W and Vault20W are models with weak mortar and bearing walls $0.2 \mathrm{~m}$ thick.

- Flat20N and Vault20N are models with normal mortar and bearing walls $0.2 \mathrm{~m}$ thick.

- Flat20S and Vault20S are models with strong mortar and bearing walls $0.2 \mathrm{~m}$ thick.

- Flat40N and Vault40N are models with normal mortar and bearing walls $0.4 \mathrm{~m}$ thick.

- Flat20R and Vault20R are models with normal mortar, bearing walls $0.2 \mathrm{~m}$ thick, six wooden columns supporting each bearing wall, two wooden columns supporting each nonbearing wall, and four wooden beams around the base of the roof. It is assumed that the bottom elements of the wooden columns are fixed to the ground, and that all the wooden members are connected to other members with mortar.

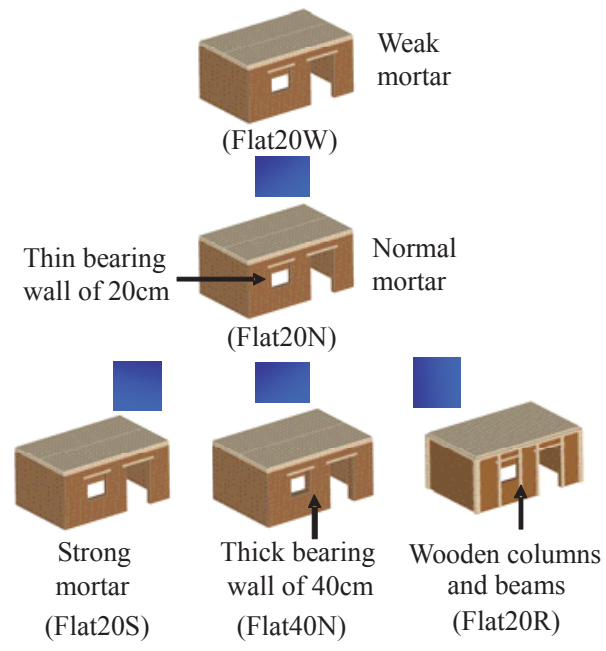

(a) Flat roof model 


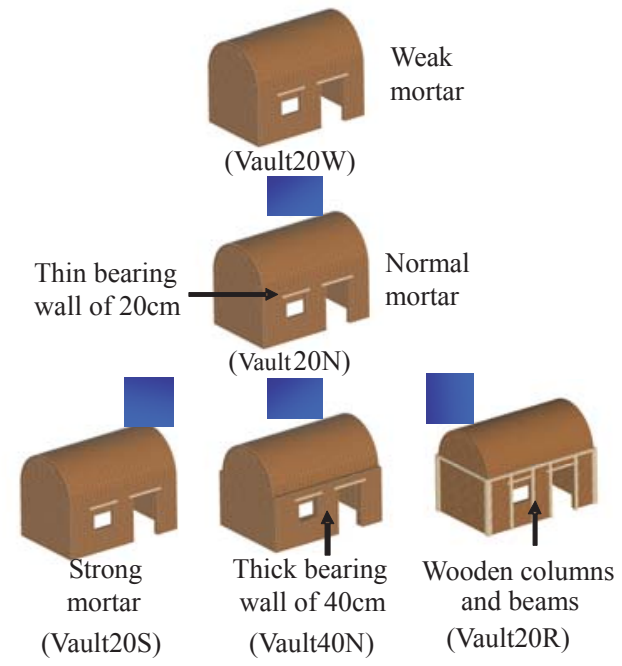

(b) Vault roof model

Fig. 7 Analytical cases

\subsection{Material properties}

Table 3 presents the material properties. The mass density and Young's modulus of adobe brick are chosen on the basis of experimental results for adobe bricks obtained by Ghannand et al. [6]. The mass density and Young's modulus of the mortar are assumed to be the same as those of the adobe brick. The material properties for the wooden columns and beams are listed in Table 3.

Structural damping is assumed to be $2 \%$ mass-proportional damping. The value of $\alpha$, which defines the mass-proportional damping, is obtained so that the damping constant for the first natural frequency in the $y$ direction is $2 \%$. The computation of the natural frequency is described in Section 3.5.

\subsection{Natural frequency}

The history of impact acceleration in the $x$ and $y$ directions is input separately for investigating the natural vibration characteristics in each direction. The impact acceleration is first input into the undamped masonry models, and the displacement histories of elements 1 and 2 (Fig. 6) are computed. Element 1 is located at the center of the nonbearing wall at a height of $2.0 \mathrm{~m}$, and element 2 is at the center of the bearing wall at a height of $2.0 \mathrm{~m}$. The time interval of the impact acceleration is $0.01 \mathrm{~s}$, the acceleration at the first time step is set as $1 \mathrm{~m} / \mathrm{s}^{2}$, and the acceleration for the rest of the time is set as $0 \mathrm{~m} / \mathrm{s}^{2}$.

Table 4 lists the first natural frequencies in each direction obtained by Fourier transformation of the free-

Table 2 Analytical cases

\begin{tabular}{|c|c|c|c|c|}
\hline Model name & Roof type & $\begin{array}{l}\text { Thickness of } \\
\text { bearing wall }\end{array}$ & Mortar strength & Reinforcement measure \\
\hline Flat20W & \multirow{5}{*}{ Flat } & \multirow{3}{*}{$20 \mathrm{~cm}$} & Weak & 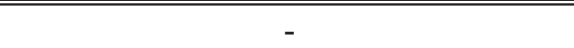 \\
\hline Flat20N & & & Normal & - \\
\hline Flat20S & & & Strong & Increasing mortar strength \\
\hline Flat40N & & $40 \mathrm{~cm}$ & Normal & Increasing thickness of bearing wall \\
\hline Flat20R & & $20 \mathrm{~cm}$ & Normal & Introducing wooden columns and beams \\
\hline Vault20W & \multirow{4}{*}{ Vault } & \multirow{3}{*}{$20 \mathrm{~cm}$} & Weak & - \\
\hline Vault20N & & & Normal & - \\
\hline Vault20S & & & Strong & Increasing mortar strength \\
\hline Vault40N & & $40 \mathrm{~cm}$ & Normal & Increasing thickness of bearing wall \\
\hline Vault20R & & $20 \mathrm{~cm}$ & Normal & Introducing wooden columns and beams \\
\hline
\end{tabular}

Table 3 Material properties

\begin{tabular}{|c||c|c|c|}
\hline Variable & Adobe brick & Mortar & Wood \\
\hline \hline Mass density $\left(\mathrm{kg} / \mathrm{m}^{3}\right)$ & $1.8 \times 10^{3}$ & $1.8 \times 10^{3}$ & $7.0 \times 10^{2}$ \\
\hline Young's modulus $\left(\mathrm{N} / \mathrm{m}^{2}\right)$ & $9.8 \times 10^{7}$ & $9.8 \times 10^{7}$ & $0.3 \times 10^{8}$ \\
\hline Poisson's ratio & 0.25 & 0.25 & 0.3 \\
\hline \multirow{2}{*}{ Structural damping } & \multicolumn{3}{|c|}{ mass-proportional damping } \\
& \multicolumn{3}{|c}{$(2 \%$ damping at the first-order natural frequency) } \\
\hline
\end{tabular}


Table 4 First-order natural frequencies

\begin{tabular}{|c||c|c|c|}
\hline \multicolumn{1}{|c||}{ Model name } & Roof type & $x$ direction & $y$ direction \\
\hline \hline \multirow{2}{*}{$\begin{array}{c}\text { Flat20S/Flat20N/Flat20S } \\
\text { Vault20S/Vault20N/Vault20S }\end{array}$} & Flat & $6.64 \mathrm{~Hz}$ & $6.05 \mathrm{~Hz}$ \\
\cline { 2 - 4 } & Vault & $3.91 \mathrm{~Hz}$ & $3.13 \mathrm{~Hz}$ \\
\hline $\begin{array}{c}\text { Flat40N } \\
\text { Vault40N }\end{array}$ & Flat & $7.03 \mathrm{~Hz}$ & $6.08 \mathrm{~Hz}$ \\
\hline \multirow{2}{*}{$\begin{array}{c}\text { Flat20R } \\
\text { Vault20R }\end{array}$} & Vault & $4.49 \mathrm{~Hz}$ & $3.32 \mathrm{~Hz}$ \\
\cline { 2 - 4 } & Flat & $6.84 \mathrm{~Hz}$ & $6.45 \mathrm{~Hz}$ \\
\hline
\end{tabular}

vibration responses. The value in the $x$ direction is obtained from the response of the center of gravity of element 1 , and the value in the $y$ direction is obtained from the response of the center of gravity of element 2 .

The input acceleration is low enough to prevent failure of the mortar, so difference due to the mortar strength is not presented. Models with a flat roof have higher natural frequencies than those with a vault roof since wooden beams are stiffer and lighter than adobe bricks. Models with thick bearing walls have the highest natural frequencies in the $x$ direction and second-highest natural frequency in the $y$ direction. The models with wooden columns and beams have the second-highest natural frequency in the $x$ direction and the highest natural frequency in the $y$ direction.

\subsection{Time interval}

Substituting the material properties listed in Table 3 and the dimension of each element into Eq. (19), $\Delta t \leq$ $5.03 \times 10^{-5} \mathrm{~s}$ is obtained for all cases. Therefore, the time interval of $\Delta t=5.0 \times 10^{-5} \mathrm{~s}$ is used.

\subsection{Input ground motion}

The Building and Housing Research Center in Iran recorded the unique main shock of the Bam earthquake [19]. The maximum accelerations of the two horizontal $(T, L)$ and vertical $(V)$ components of the earthquake after correction were $6.2344 \mathrm{~m} / \mathrm{s}^{2}(T), 7.7828$ $\mathrm{m} / \mathrm{s}^{2}(L)$, and $9.7995 \mathrm{~m} / \mathrm{s}^{2}(V)$ (Figs. 8 (a) - (c)). The direction of the accelerometer for the $L$ component is N278E. The vertical component is very large. For the horizontal components, the peak ground acceleration of the $L$ component is greater than that of the $T$ component.

Figure 9 presents the displacement response spectra of the three components for a damping coefficient of $2 \%$. Figure 9 (a) is the response spectrum for the ground motion from 0 to $3.5 \mathrm{~s}$. Of the horizontal components, it is found that the $L$ component is dominant from 0 to $3.5 \mathrm{~s}$. Figure 9 (b) is the response spectrum for the ground motion from 0 to $10 \mathrm{~s}$. The $L$ component is less than the $T$ component for a natural frequency of less than $6 \mathrm{~Hz}$ and is greater than the $T$ component for a natural frequency greater than $6 \mathrm{~Hz}$. All vault roof models have natural frequencies of less than $6.0 \mathrm{~Hz}$ (Table 4), so the $T$ component is dominant for the vault models from 3.5 to $10 \mathrm{~s}$. Although all flat roof models have natural frequencies higher than $6.0 \mathrm{~Hz}$, the natural frequencies decrease as the failure proceeds, so it can be concluded that the $T$ component is dominant in the failure process after 3.5 s except for the flat models, such as Flat20S, which do not show remarkable failure behavior. From these findings, $T$ is referred to as the latter dominant component and $L$, the initial dominant component in this study. The gravitational acceleration is considered to be $\mathbf{g}=\left\{\begin{array}{lll}0.0 & 0.0 & -9.8\end{array}\right\}^{T}$.

Two cases for the input ground motion direction are considered as presented in Table 5. In the case of $\mathrm{TLV}$, the $T, L$, and $V$ components are input in the $x, y$, and $z$ directions, respectively. In the case of LTV, the $L$, $T$, and $V$ components are input in the $x, y$, and $z$ directions, respectively.

In the analysis, the gravitational force is input first. After structural stability under gravitational force is confirmed, the ground motion is input. We confirmed that all models stand stably under gravitational force without failure. 


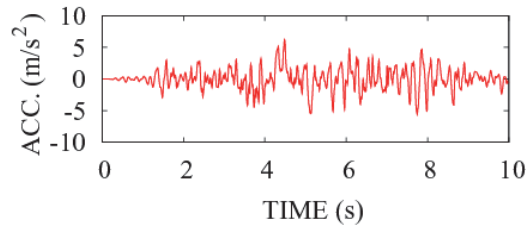

(a) $T$ component

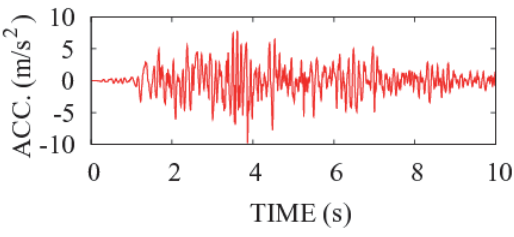

(b) $L$ component

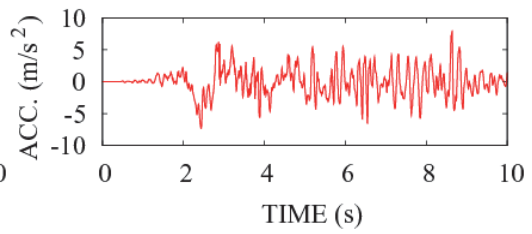

(c) $V$ component

Fig. 8 Time histories of input ground motion

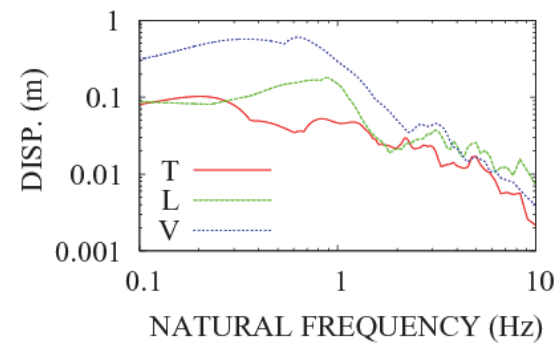

(a) $0-3.5 \mathrm{~s}$

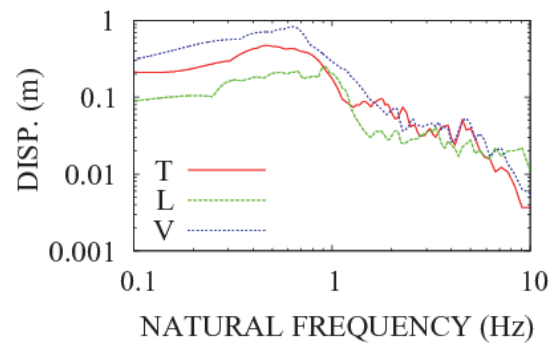

(b) $0-10 \mathrm{~s}$

Fig. 9 Displacement response spectra for a damping coefficient of $2 \%$

Table 5 Cases of the input ground motion direction

\begin{tabular}{|c||c|c|c|}
\hline Case & $x$ direction & $y$ direction & $z$ direction \\
\hline \hline TLV & $T$ component & $L$ component & $V$ component \\
\hline LTV & $L$ component & $T$ component & $V$ component \\
\hline
\end{tabular}

\section{Results}

\subsection{Failure propagation of flat roof models (1) Flat20W}

The seismic behavior of the flat roof model with weak mortar (Flat20W) is shown in Figs. 10 and 11 for the TLV and LTV cases, respectively. Failure propagation is expressed in the following manner. The face of an element where no failure occurs is shown in light gray. The face of an element where the mortar connection is broken by tensile failure is shown in red and surrounded by black lines. Neither shear nor compression failure occurred.

\section{a) TLV (Fig. 10)}

Since the mortar is weak, there was tensile failure throughout the walls. Tensile failure occurred first in the bearing wall at $1.20 \mathrm{~s}$ as shown in the picture and then in the nonbearing wall at $2.00 \mathrm{~s}$ as shown in the picture. The roof beams on both edges then separated at $2.80 \mathrm{~s}$ owing to the different vibration characteristics of the two walls. There were diagonal cracks around the openings in the bearing wall at $4.80 \mathrm{~s}$, and the nonbearing walls then failed from the top and bricks of the nonbearing walls fell. The bearing walls did not fall, so the roof did not collapse.
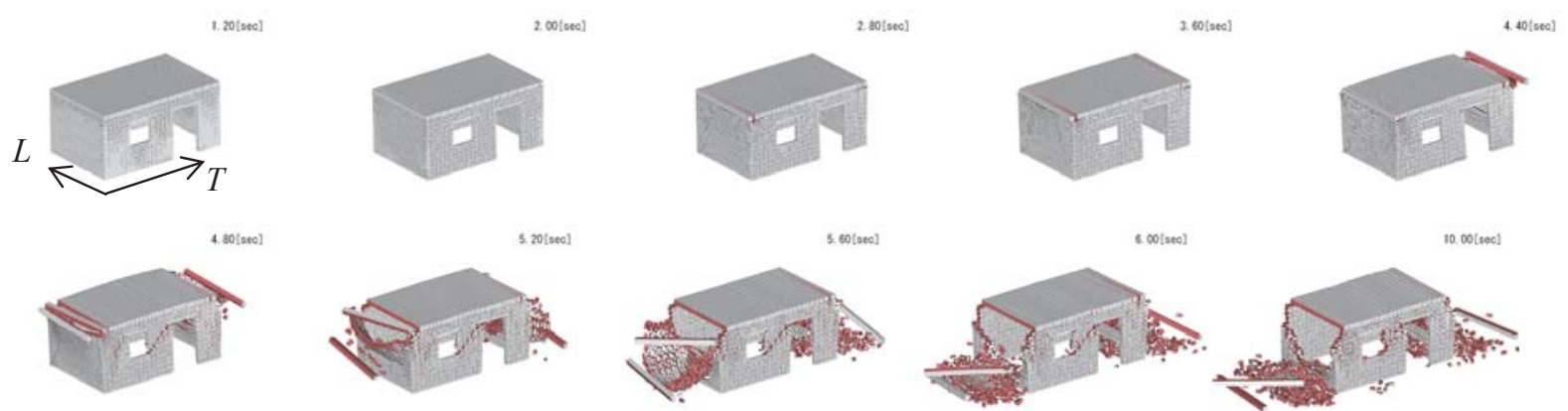

Fig. 10 Seismic behavior of Flat20W, TLV 

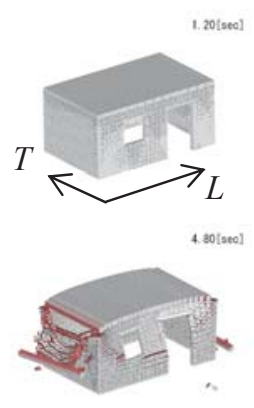
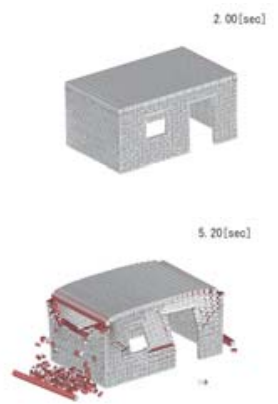
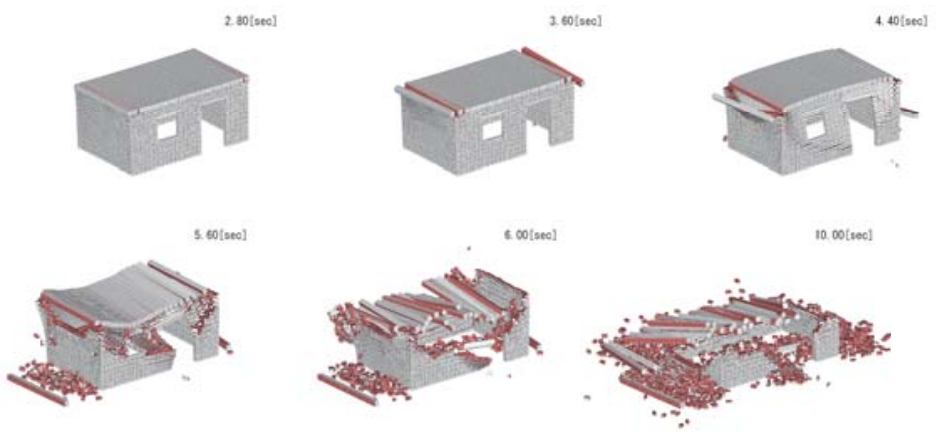

Fig. 11 Seismic behavior of Flat20W, LTV

\section{b) LTV (Fig. 11)}

Similar to the case of TLV, there was tensile failure throughout the walls, first in the bearing wall and then in the nonbearing wall. Separation of roof beams at both edges is also seen. Deformation of the bearing wall in the out-of-plane direction is seen at 4.4 $\mathrm{s}$, which is not seen in the case of TLV. There were horizontal cracks in the bearing wall at $4.80 \mathrm{~s}$, and the roof then collapsed with the failure of the bearing walls.

\section{c) Effect of the input ground motion direction}

In the case of LTV, since the latter dominant component, $T$, is input in the out-of-plane direction of the bearing wall, the bearing wall deforms more readily, leading to the total collapse of the roof. The increase in out-of-plane deformation increases the $\mathrm{P}-\Delta$ effect of the roof weight, where roof weight $\mathrm{P}$ acting on the bearing wall with deformation $\Delta$ enforces a moment of $\mathrm{P} \Delta$ on the bearing wall, and thus, the building collapses.

In the case of TLV, the latter dominant component, $T$, is input in the in-plane direction of the bearing wall, and clear diagonal cracks are seen in the bearing wall. However, deformation of the bearing walls in the outof-plane direction is smaller and the walls do not fall, which prevents the total collapse of the roof.

The initial dominant component, $L$, affects the initial failure propagation, but the time in which the $L$ component is dominant is short. Therefore, the collapse process is dominated by the latter and longer dominant component, $T$.

It is thus found that the total collapse of a building depends on the integrity of the bearing walls against input acceleration.

\section{(2) Flat20N}

The seismic behavior of the flat roof model with normal mortar (Flat20N) is shown in Figs. 12 and 13 for the TLV and LTV cases, respectively. Figures 12 (a) and 13 (a) are the front views and Figs. 12 (b) and 13 (b) are the rear views. Elements 1, 2, and 3 are elements whose histories of displacement are presented later in the paper. Failure propagation is expressed in a manner similar to that for Flat20W. Neither shear nor compression failure occurred.

\section{a) TLV (Fig. 12)}

As seen in Fig. 12 (a), there was no tensile failure of the walls. First, diagonal cracks formed from the corner of the openings in the bearing wall at $2.00 \mathrm{~s}$ as shown in the picture. Horizontal cracks are also seen between the window and door openings. The number of diagonal and horizontal cracks then increased in the bearing wall at $2.80 \mathrm{~s}$. There were vertical cracks at the edge of the bearing wall with openings at $3.60 \mathrm{~s}$. These vertical cracks allowed the nonbearing wall to move more easily, and horizontal cracks formed in the nonbearing wall at $4.80 \mathrm{~s}$. As seen in Fig. 12 (b), there were no diagonal cracks in the bearing wall without openings. Horizontal cracks were generated by outof-plane deformation.

\section{b) LTV (Fig. 13)}

Similar to the case of TLV, there were diagonal cracks and horizontal cracks in the bearing wall with openings at $2.00 \mathrm{~s}$ as seen in Fig. 13 (a). Vertical cracks in the bearing wall generated at $2.80 \mathrm{~s}$, earlier than in the case of TLV. The bearing wall then deformed in the out-of-plane direction at $6.00 \mathrm{~s}$ and fell in this direction. The roof collapsed with the failure of the bearing wall with openings. As seen in Fig. 13 (b), the opposite bearing wall without openings deformed at $6.00 \mathrm{~s}$ because the roof pushed the wall outward, and it lost its balance and fell with the roof. 

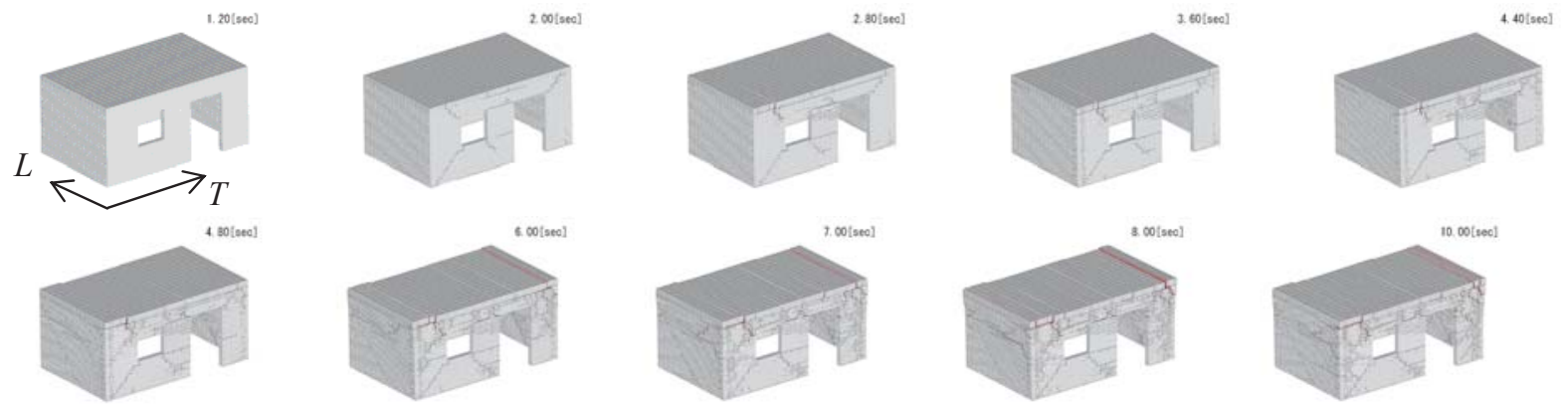

(a) Front view
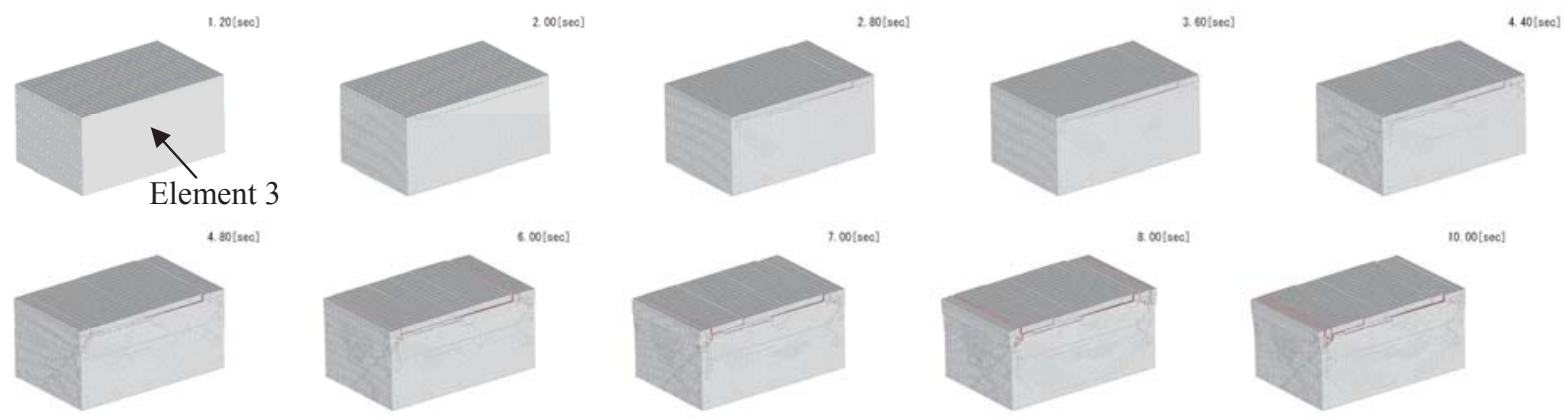

(b) Rear view

Fig. 12 Seismic behavior of Flat20N, TLV
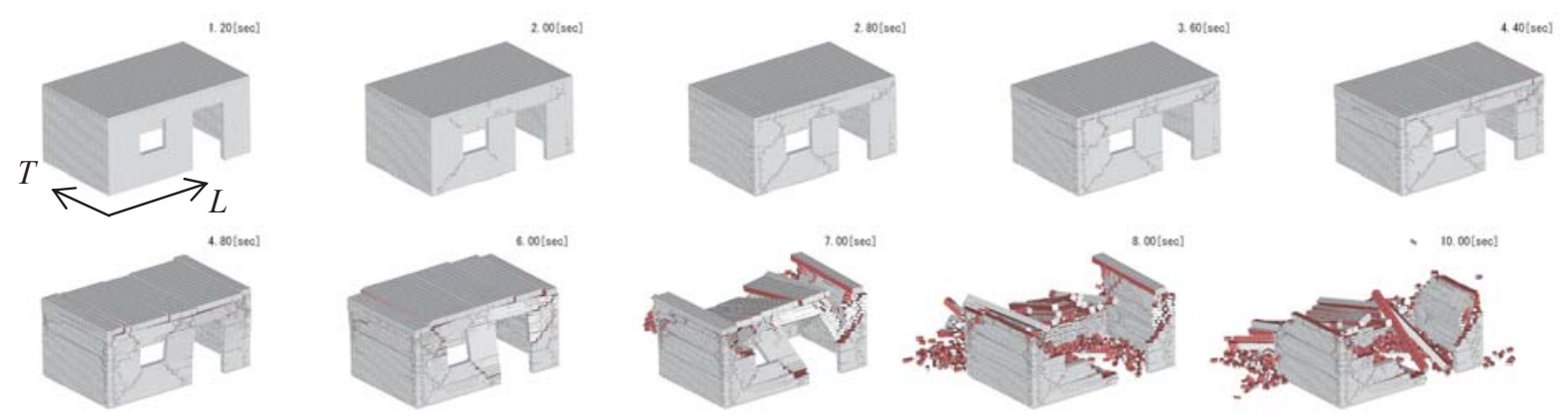

(a) Front view
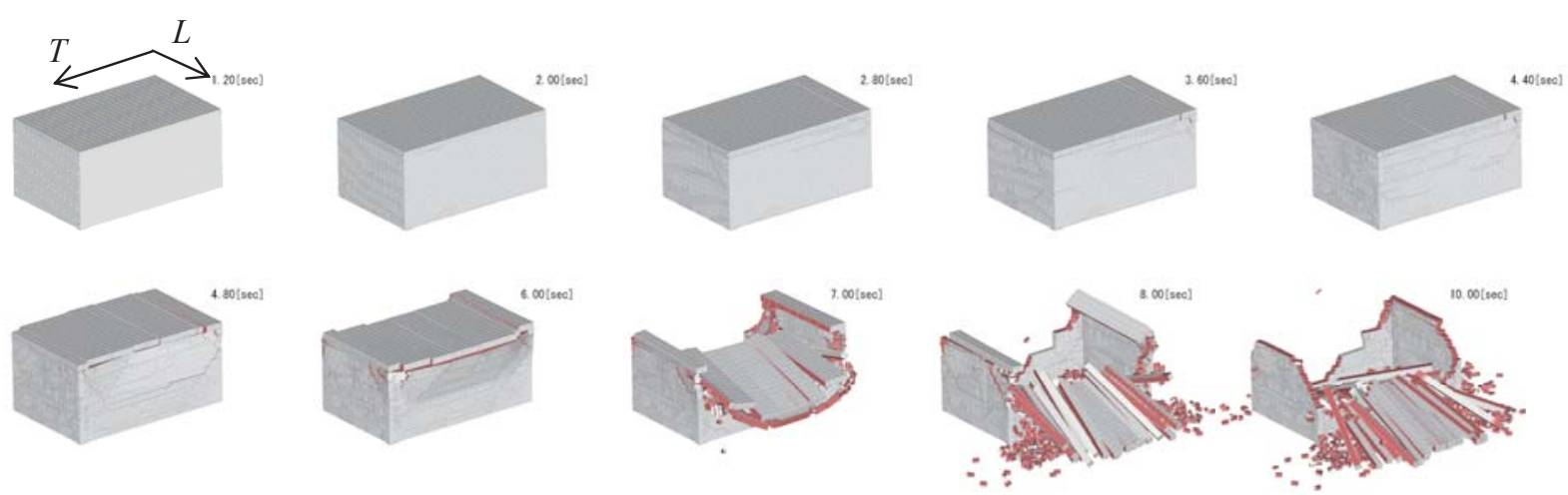

(b) Rear view

Fig. 13 Seismic behavior of Flat20N, LTV 


\section{c) Effect of the input ground motion direction}

The building collapsed in the case of LTV but not in the case of TLV. In the LTV case, the initial dominant component, $L$, deformed the load-bearing wall in the in-plane direction and generated diagonal and horizontal cracks. The latter dominant component, $T$, then deformed the load-bearing wall so that it collapsed in the out-of-plane direction. The direction of the input ground motion is important as it controls the occurrence of structural collapse.

\section{(3) Flat20S}

The seismic behavior of the flat roof model with strong mortar (Flat20S) is shown in Figs. 14 and 15 for the TLV and LTV cases, respectively. There was tensile failure but no shear or compression failure.

\section{a) TLV (Fig. 14)}

In the case of TLV, there was only tensile failure between the floor and the bearing wall. There was no failure of the walls or roof. Failure occurred at $3.40 \mathrm{~s}$, at which time the $L$ component was dominant. The $L$ component made the bearing wall move in the out-ofplane direction and generated cracks at the base of the wall.

\section{b) LTV (Fig. 15)}

In the case of LTV, diagonal and horizontal cracks formed in the bearing wall at $3.40 \mathrm{~s}$, at which time the $L$ component was dominant. The $L$ component deformed the bearing wall in the in-plane direction and generated these cracks.

\section{c) Effect of the input ground motion direction}

For the flat roof models with strong mortar, the initial dominant component, $L$, generated a small number of cracks with peak ground acceleration in both cases. The latter dominant component, $T$, did not generate cracks.

\section{d) Effect of mortar strength}

From a comparison of Figs. 10-15, the effect of mortar is clear. Increasing mortar strength is effective in preventing the collapse of structures.

\section{(4) Flat40N}

The seismic behavior of the flat roof model with thick bearing walls and normal mortar (Flat40N) is shown in Figs. 16 and 17 for the TLV and LTV cases, respectively. There was tensile failure but no shear or compression failure.

\section{a) TLV (Fig. 16)}

Compared with the Flat20N model (Fig. 12), there were few cracks in the bearing wall. However, the crack patterns in the walls were similar to those of Flat20N.

\section{b) LTV (Fig. 17)}

Compared with the Flat20N model (Fig. 13), the crack patterns in the walls were similar, but the number of cracks and the out-of-plane deformation of the bearing wall were smaller and the structure did not collapse.

\section{c) Effect of the thickness of the bearing wall}

By increasing the thickness of the bearing wall, the number of cracks decreased and the structure did not collapse in the case of LTV. Thus, increasing the thickness of bearing walls is also effective in increasing the seismic resistance of a structure.
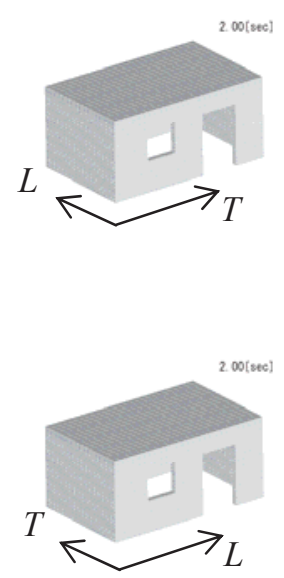
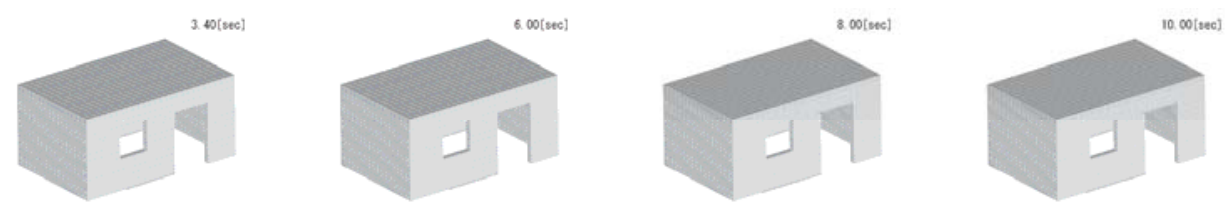

Fig. 14 Seismic behavior of Flat20S, TLV
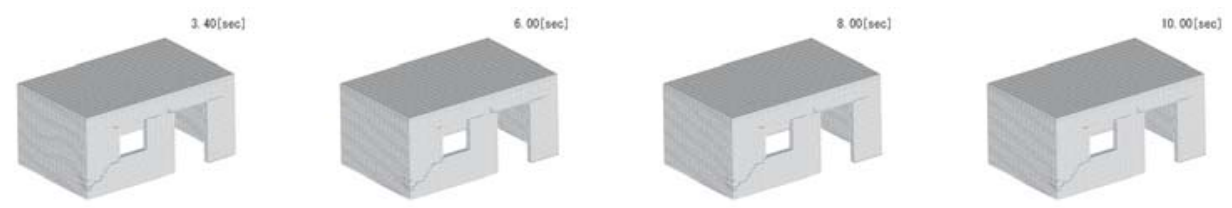

Fig. 15 Seismic behavior of Flat20S, LTV 

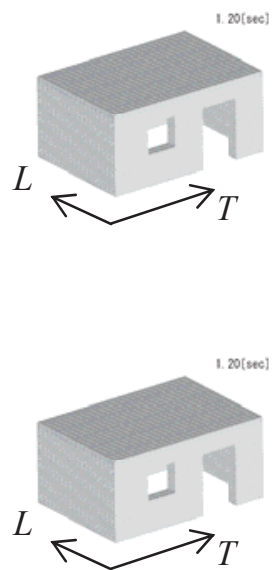
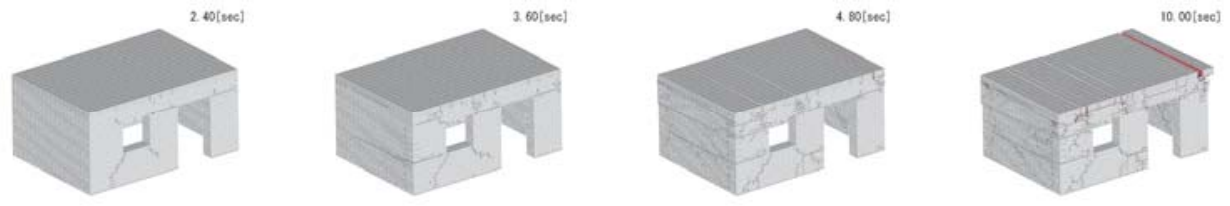

Fig. 16 Seismic behavior of Flat40N, TLV
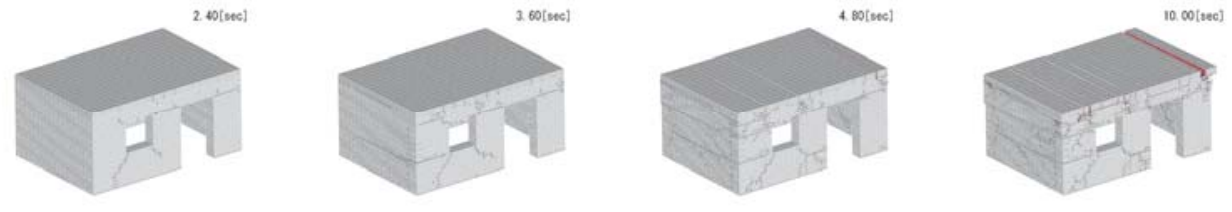

Fig. 17 Seismic behavior of Flat40N, LTV

\section{(5) Flat20R}

The seismic behavior of the flat roof model with wooden columns and beams and normal mortar (Flat20R) is shown in Figs. 18 and 19 for the TLV and LTV cases, respectively. There was tensile failure but no shear or compression failure.

\section{a) TLV (Fig. 18)}

Compared with the Flat20N model (Fig. 12), there were fewer cracks in the bearing wall. The crack patterns in the walls also differed and there were fewer diagonal cracks.

\section{b) LTV (Fig. 19)}

Compared with the Flat20N model (Fig. 13), the crack patterns in the walls differed. In addition, there were fewer cracks and less out-of-plane deformation of the bearing wall, and the bearing wall did not collapse.

\section{c) Effect of wooden columns and beams}

By introducing wooden columns and beams, the num- ber of cracks, especially diagonal cracks, decreased, and the structure did not collapse in the case of LTV. Reinforcement using wooden columns and beams is thus also found to be effective.

\section{(6) Comparison of reinforcement measures}

From a comparison of Flat20W, Flat20N, and Flat20S, it is successfully simulated that increasing the mortar strength effectively increases the seismic strength of the model, which is natural since failure is only introduced in the mortar. We can also see how the failure behaviors differ depending on the mortar strength.

In addition, from a comparison of Flat20N, Flat40N, and Flat20R, it is found that increasing the thickness of the bearing walls and reinforcement with wooden columns and beams also increases the seismic strength of the model even though many cracks are generated in the walls.
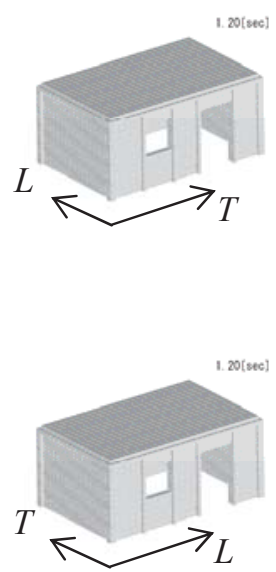
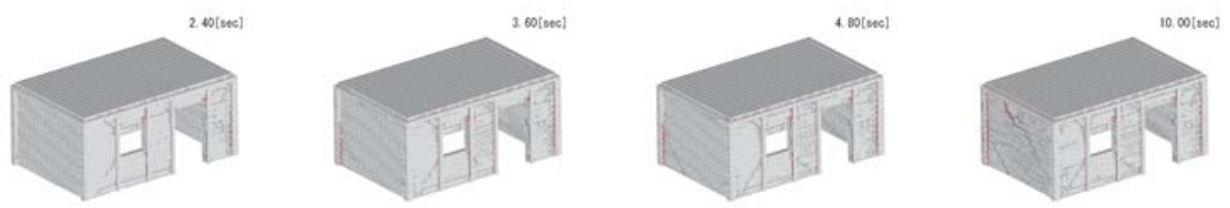

Fig. 18 Seismic behavior of Flat20R, TLV
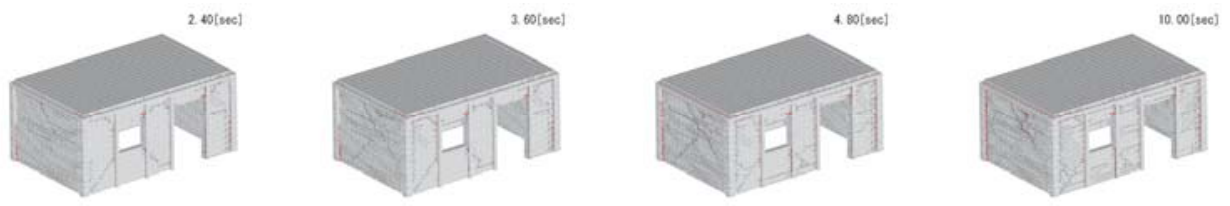

Fig. 19 Seismic behavior of Flat20R, LTV 
The displacement histories of Flat20S, Flat40N, and Flat20R are compared with those of Flat20N to investigate the effectiveness of increasing the mortar strength, increasing the thickness of the walls, and introducing wooden columns and beams.

Figures 20 and 21 show the histories of displacement of elements 1, 2, and 3. Element 1 is at the center of the nonbearing wall, so its out-of-plane direction, $x$, is investigated. On the other hand, elements 2 and 3 are at the centers of the bearing walls, so their out-ofplane direction, $y$, is investigated. The height of these elements is $2.0 \mathrm{~m}$. Figures 20 and 21 show the results for the TLV and LTV cases, respectively. Since the Flat20N model collapsed in the case of LTV, the history of Flat $20 \mathrm{~N}$ is off the scale in Figs. 21 (b) and (c).

By comparing Fig. 20 (a) with Fig. 21 (a), it can be seen that the LTV case (Fig. 21 (a) ) has larger amplitudes in the $x$ direction at $0-3.5 \mathrm{~s}$ because the larger $L$ component results in larger displacement. Similarly, the TLV case (Figs. 20 (b) and (c) ) has larger amplitudes in the $y$ direction at $0-3.5 \mathrm{~s}$. Later, there is a tendency for the amplitude in the other direction to be larger.

Comparing Flat20N and Flat40N, the displacement of element 1 on the nonbearing wall is similar since the thickness of the nonbearing wall is the same. On the other hand, the displacements of elements 2 and 3 on the bearing walls differ between Flat20N and Flat40N since the bearing walls of Flat $40 \mathrm{~N}$ are thicker. By increasing the thickness of the bearing wall, the out-ofplane deformation decreases, which prevents collapse in the case of LTV.

Compared with the displacements of Flat $20 \mathrm{~N}$ and Flat40N, those of Flat20R and Flat20S are much smaller for the three elements in both directions. The effectiveness of increasing the mortar strength and reinforcement with wooden columns beams is clear and is superior to increasing the thickness of the bearing walls. Flat20S has less displacement, so increasing the mortar strength is found to be the most effective approach. Flat20R is the second-best model in terms of reducing the displacement response.

\section{(7) Summary of the failure propagation process}

The failure propagation process of the flat roof models is summarized as follows.

1) Diagonal and horizontal cracks form in walls from the corners of openings.

2) These cracks increase the out-of-plane deformation of the roof.

3) The out-of-plane deformation induces vertical cracks in the corners.
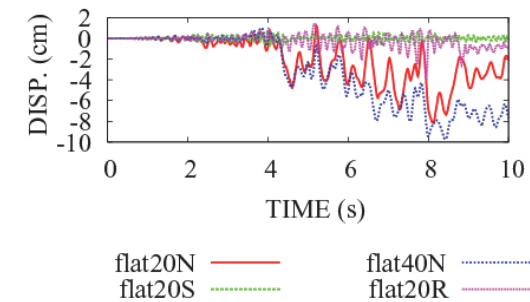

(a) Element 1, $x$

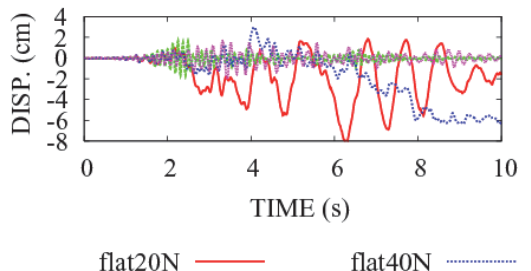

flat $40 \mathrm{~N}$
flat $20 \mathrm{~N}-\ldots \ldots \ldots$

(b) Element 2, $y$

Fig. 20 History of displacement, TLV

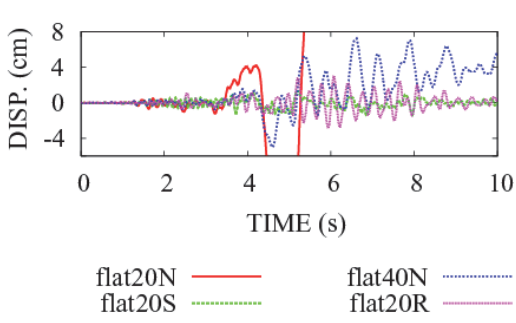

(b) Element 2, $y$
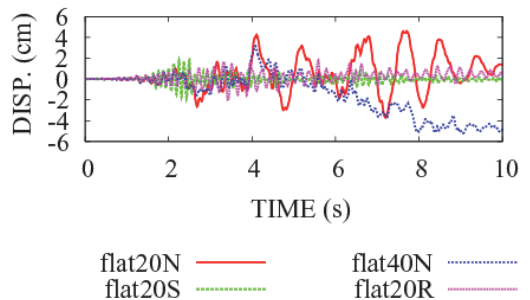

(c) Element 3, y

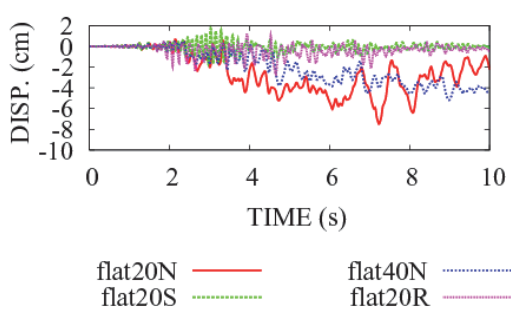

(a) Element 1, $x$

Fig. 21 History of displacement, LTV

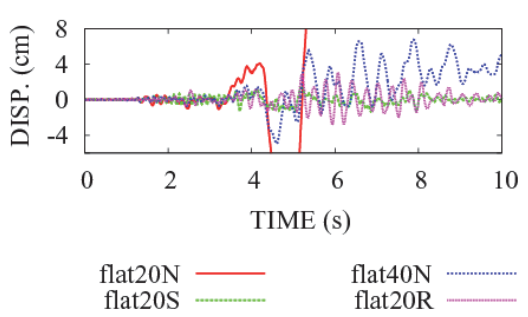

(c) Element 3, y 
4) The vertical cracks separate wall-to-wall connections.

5) The out-of-plane deformation of walls increases since walls can move more independently.

6) The increase in out-of-plane deformation increases the $\mathrm{P}-\Delta$ effect of the roof weight.

7) The wall falls with the roof.

\subsection{Failure propagation of vault roof models} (1) Vault20W

The seismic behavior of the vault roof model with weak mortar (Vault20W) is shown in Figs. 22 and 23 for the TLV and LTV cases, respectively. The process of failure propagation is expressed in the same manner as for the flat roof models. There was neither shear nor compression failure.

In both cases of input ground motion direction, the vault roof collapsed under its own weight. The vault roof pushed the two supporting bearing walls outward, so the walls collapsed in the out-of-plane direction as soon as the simulation started. The nonbearing walls did not collapse under their own weight because they did not support the weight of the roof. Instead, the nonbearing walls collapsed in the out-of-plane direction owing to the input ground motion. No clear difference due to the direction of the input ground motion is seen since the structure collapsed mainly under its own weight owing to the instability of the roof.

\section{(2) Vault20N}

The seismic behavior of the vault roof model with normal mortar (Vault20N) is shown in Figs. 24 and 25 for the TLV and LTV cases, respectively. There was only tensile failure and no shear or compression failure.

It is confirmed that Vault20N was not damaged if there was no ground motion. However, small initial ground motion triggered movement of the roof, and this unbalanced the weight distribution and the roof collapsed. Since the vault roof pushed the bearing walls outward, the bearing wall with openings easily cracked with small input ground motion at $1.20 \mathrm{~s}$ as seen in the picture. The difference in the failure process due to the direction of the input ground motion was small. In both cases, the bearing walls started collapsing with the small initial ground motion, and the nonbearing walls collapsed later with larger amplitudes of ground motion.
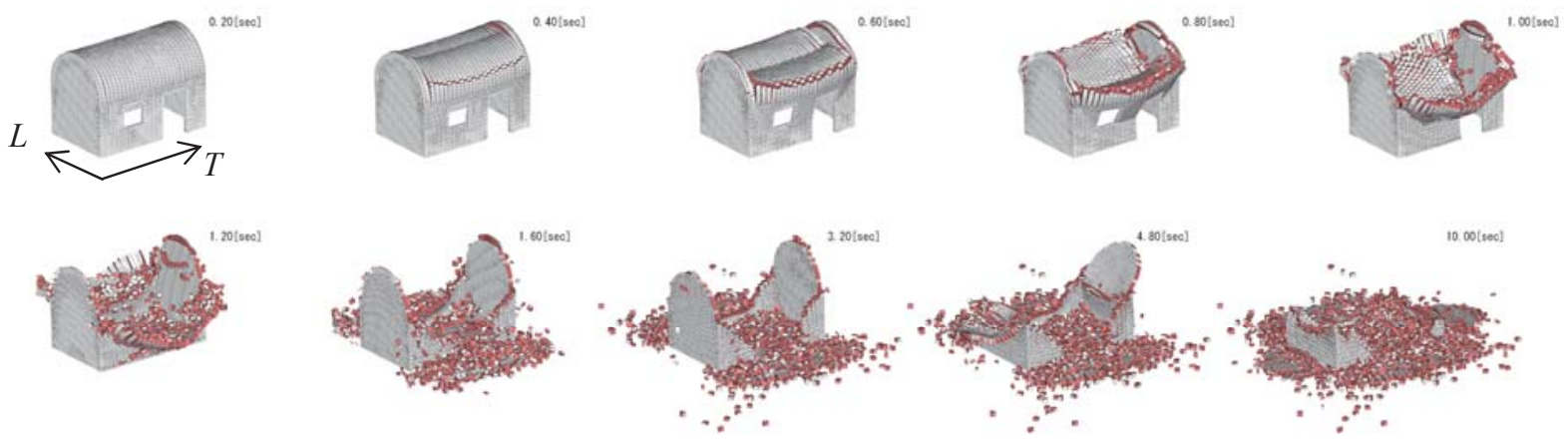

Fig. 22 Seismic behavior of Vault20W, TLV
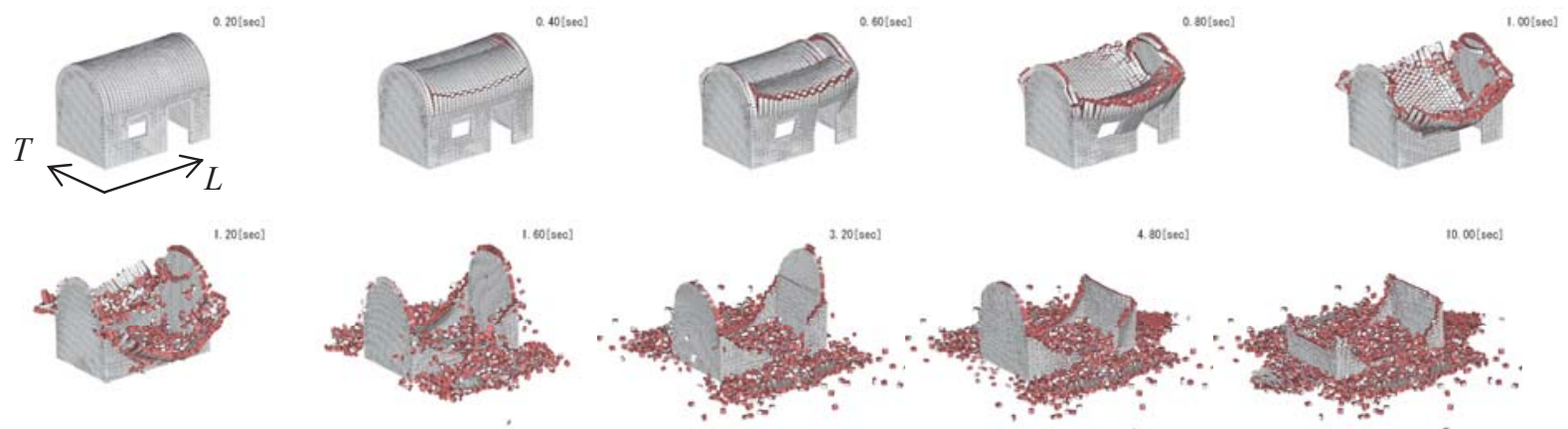

Fig. 23 Seismic behavior of Vault20W, LTV 

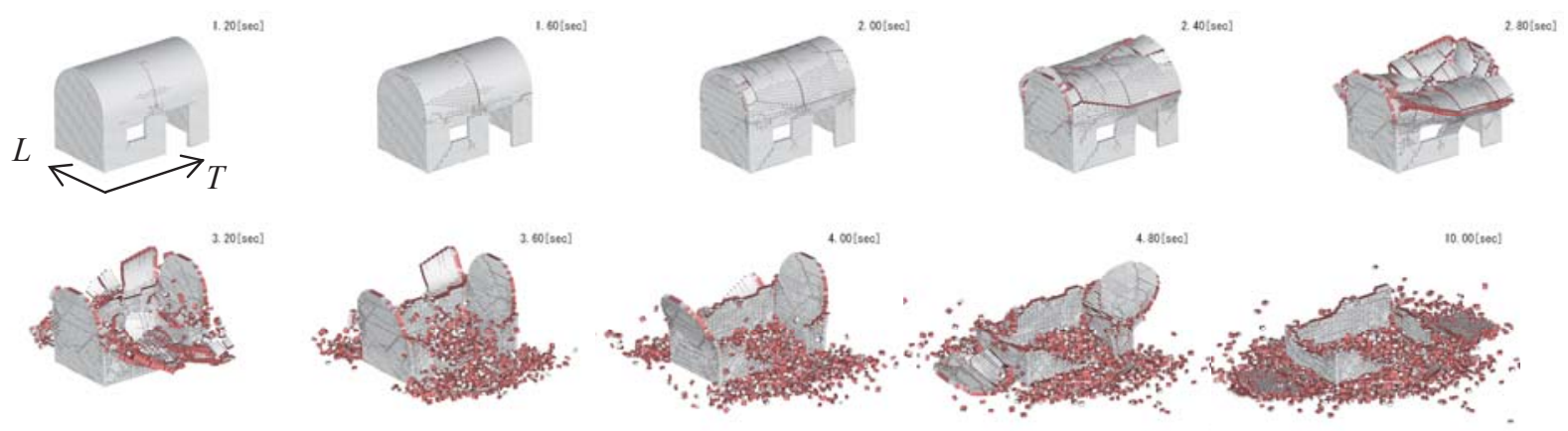

Fig. 24 Seismic behavior of Vault20N, TLV
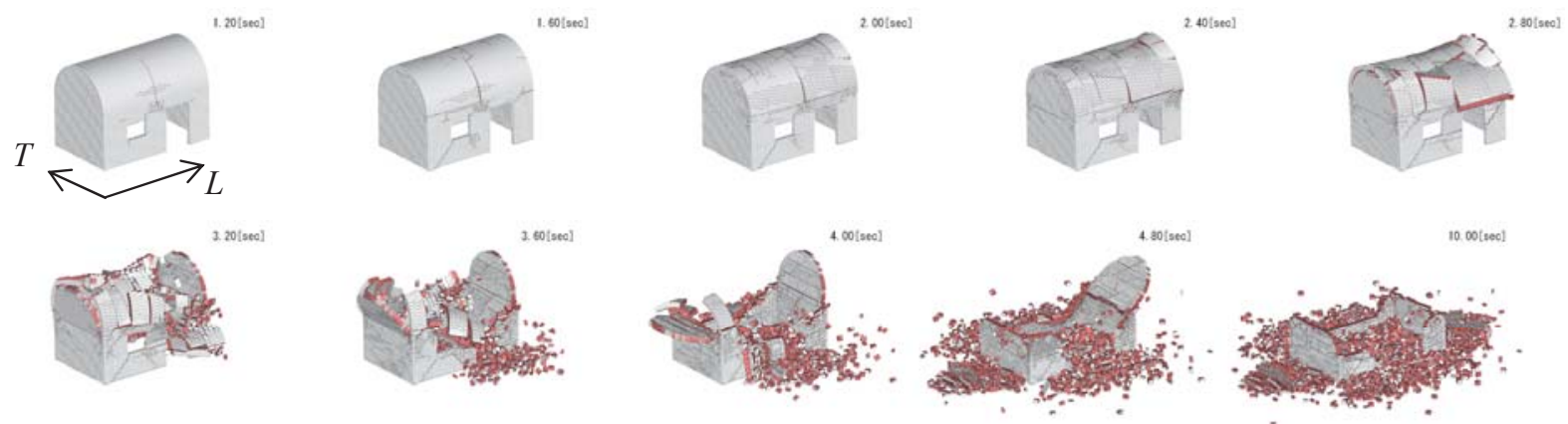

Fig. 25 Seismic behavior of Vault20N, LTV

\section{(3) Vault20S}

The seismic behavior of the vault roof model with strong mortar (Vault20S) is shown in Figs. 26 and 27 for the TLV and LTV cases, respectively. There was only tensile failure and no shear or compression failure.

Vault20S has strong mortar strength, so the structure did not collapse even though the bearing wall with openings was more cracked than in the case of Flat20S.

\section{(4) Vault40N}

The seismic behavior of the vault roof model with thick bearing walls and normal mortar (Vault40N) is shown in Figs. 28 and 29 for the TLV and LTV cases, respectively. There was only tensile failure and no compression failure.

Since the bearing walls are thicker, the roof collapsed more slowly than Vault20N as shown in Figs. 24 and 25. In the case of TLV (Fig. 28), the two bearing walls did not collapse. However, in the case of LTV (Fig. 29), the bearing wall with openings fractured since
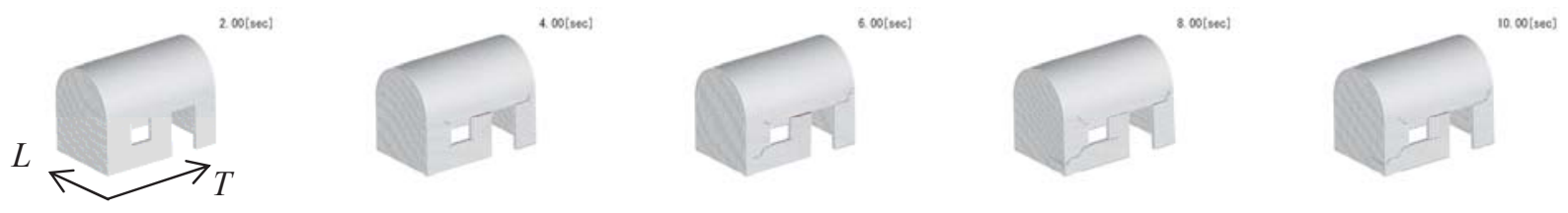

Fig. 26 Seismic behavior of Vault20S, TLV
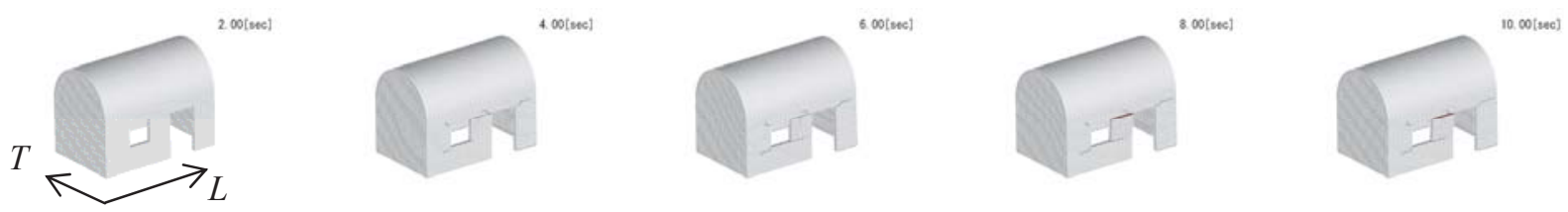

Fig. 27 Seismic behavior of Vault20S, LTV 

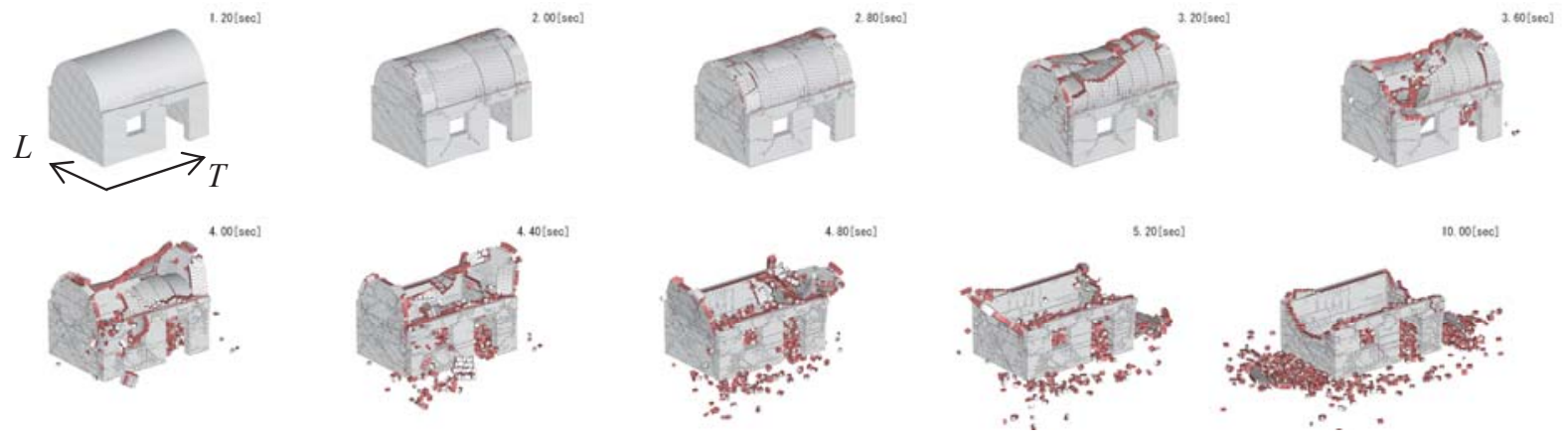

Fig. 28 Seismic behavior of Vault40N, TLV
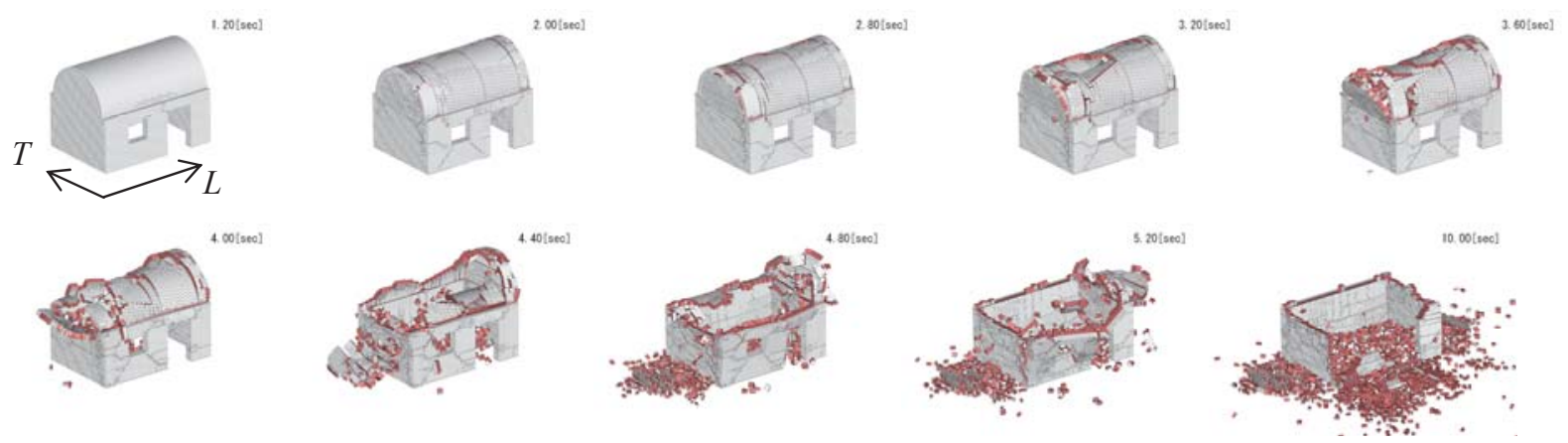

Fig. 29 Seismic behavior of Vault40N, LTV

the dominant $T$ component acted in the out-of-plane direction of the bearing wall.

For the flat roof models, structural collapse depends on the integrity of the bearing walls. Therefore, increasing the thickness of the bearing walls prevented the collapse of the roof in the case of LTV. However, for the vault roof models, the thicker bearing walls slow the collapse of the roof and they are themselves less damaged, but this does not always prevent the collapse of the roof. More specifically, if the roof itself is weak or unstable, it collapses irrespective of the strength of the bearing walls. Reinforcement of the roof is thus necessary in the first place.

\section{(5) Vault20R}

The seismic behavior of the reinforced vault roof model with normal mortar (Vault20R) is shown in Figs. 30 and 31 for the TLV and LTV cases, respectively. There was only tensile failure and no shear or compression failure.

Since the four roofs are supported by wooden columns and surrounded by wooden beams, the roof collapsed more slowly than in the case of Vault40N (Figs. 28 and 29). However, the roof did not survive the earthquake motion and collapsed during the period of large-amplitude ground motion. The wall was reinforced with wooden columns, but the bricks around the openings scattered.

\section{(6) Comparison of reinforcement measures}

The displacement histories of Vault20S, Vault40N, and Vault20R are compared with those of Vault20N to investigate the effectiveness of increasing the mortar strength, increasing the thickness of the bearing walls, and introducing wooden columns and beams. Figures 32 and 33 show the histories of displacement of elements 1,2 , and 3 .

Comparing Vault20N and Vault40N, it can be seen that elements 1 and 2 fell in both cases but the elements of Vault $40 \mathrm{~N}$ fell later than those of Vault20N, and that element 3 of Vault40N did not fall while that of Vault $20 \mathrm{~N}$ did. These findings confirm the effectiveness of increasing the thickness of bearing walls.

Comparing Vault40N and Vault20R, it can be seen that element 1 of Vault40N fell but that of Vault20R did not since the nonbearing walls of Vault20R were reinforced and those of Vault40N were not. As for element 3 , which did not fall in either model, the displacement 

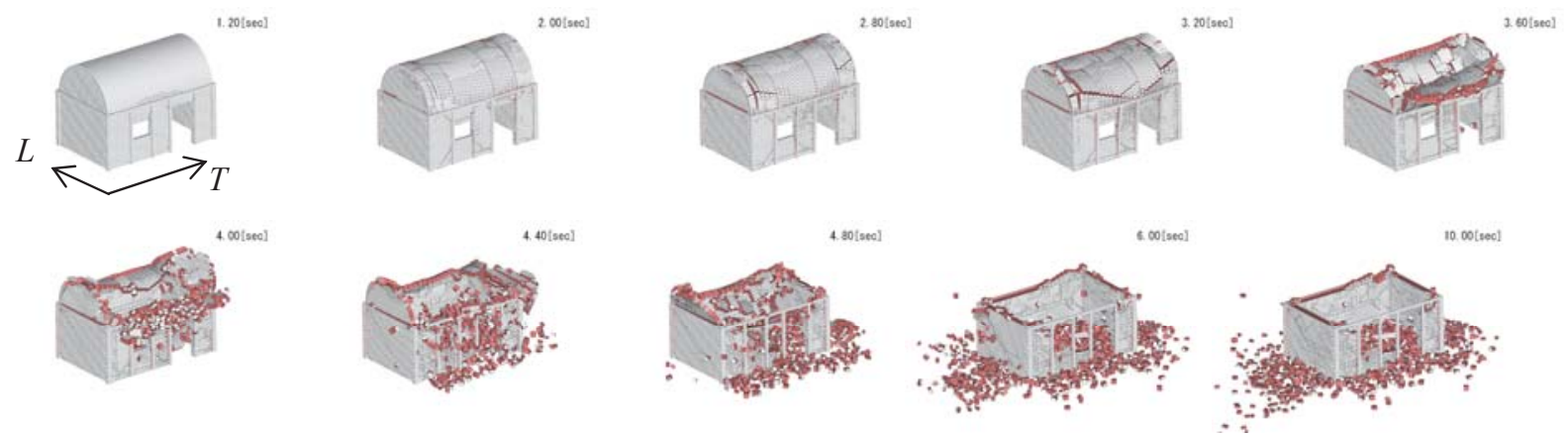

Fig. 30 Seismic behavior of Vault20R, TLV
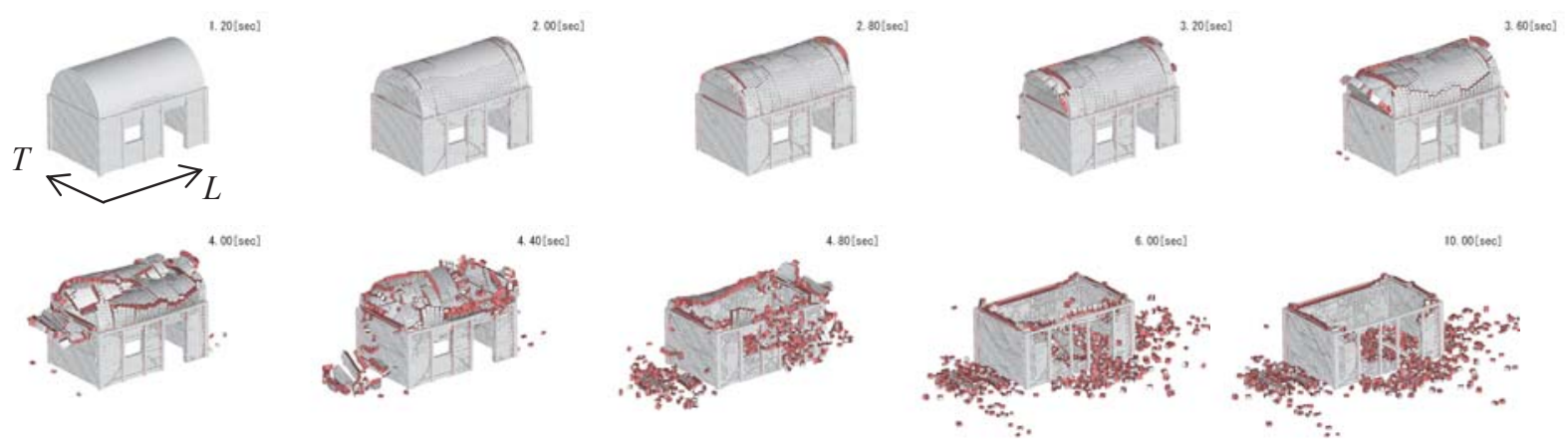

Fig. 31 Seismic behavior of Vault20R, LTV
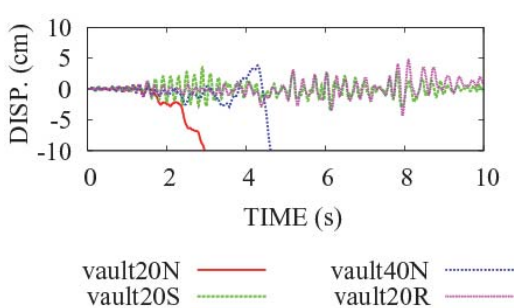

(a) Element 1, $x$

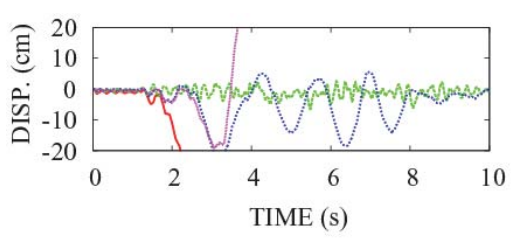

vault $20 \mathrm{~N}$ vault $20 \mathrm{~S}$

(b) Element 2, $y$

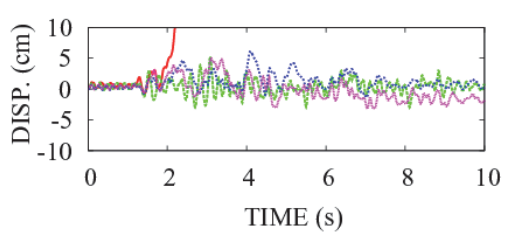

vault $20 \mathrm{~N}-\quad$ vault $40 \mathrm{~N}$ vault20R

(c) Element 3,y

Fig. 32 History of displacement, TLV

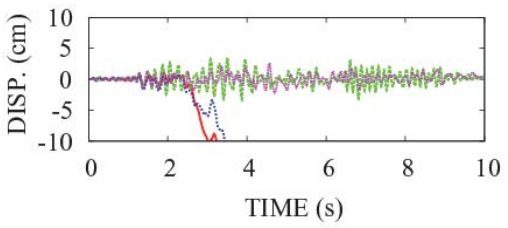

$\begin{array}{ll}\text { vault } 20 \mathrm{~N}- & \text { vault40N } \cdots \cdots \cdots \cdots \cdots . . . \\ \text { vault20 } & \text { vault20R }\end{array}$

(a) Element 1, $x$
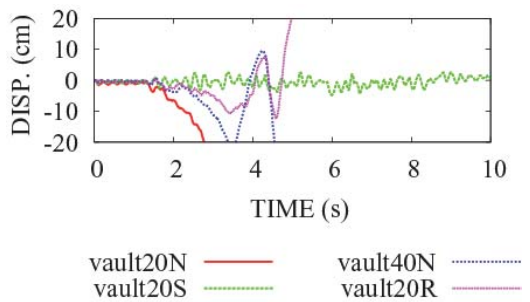

(b) Element 2,y

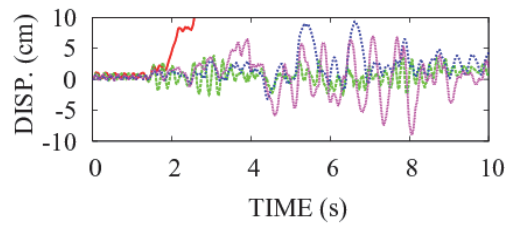

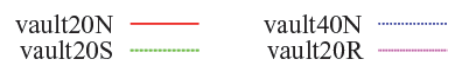

(c) Element 3, y

Fig. 33 History of displacement, LTV

of Vault20R was slightly larger than that of Vault40N in the case of LTV since the great weight of the roof pushed the bearing wall in the out-of-plane direction and the thinner walls with wooden columns deformed more easily than the thick walls without columns.

The displacement of Vault20S was the smallest among all models. It can be seen that increasing the mortar strength is the most effective approach.

\section{(7) Summary of the failure propagation process}

The failure propagation process of the vault roof models is different from that of the flat roof models, and is summarized as follows. 
1) The weight of the roof pushes the bearing walls in the out-of-plane direction.

2) With small deformation of the buildings induced by small initial ground motion, the heavy weight of the vaulted roof increases the out-of-plane deformation of the walls owing to the $\mathrm{P}-\Delta$ effect.

3) The instability of the roof increases, and the roof collapses.

4) If the bearing walls do not have sufficient strength, they collapse due to the collapse of the vaulted roof.

\subsection{Failure mechanism of past earthquake damage and simulation results \\ (1) Past earthquake damage}

Photographs 1 (a) and (b) show two houses damaged by earthquakes. Photograph 1 (a) is of a house damaged during the 2003 Bam earthquake in Iran. Photograph 1 (b) is of a house damaged during the 1976 Friuli earthquake in Italy.

In Photo 1 (a), the nonbearing walls have been demolished, but the roof has not collapsed because the bearing walls are supported by the adjacent buildings. In Photo 1 (b), the nonbearing walls are still standing, even though the roof and bearing walls have collapsed. These two cases indicate that the stability of the roof depends on the two bearing walls and that failure of the roof can be avoided if the bearing walls are supported somehow, regardless of damage to nonbearing walls.

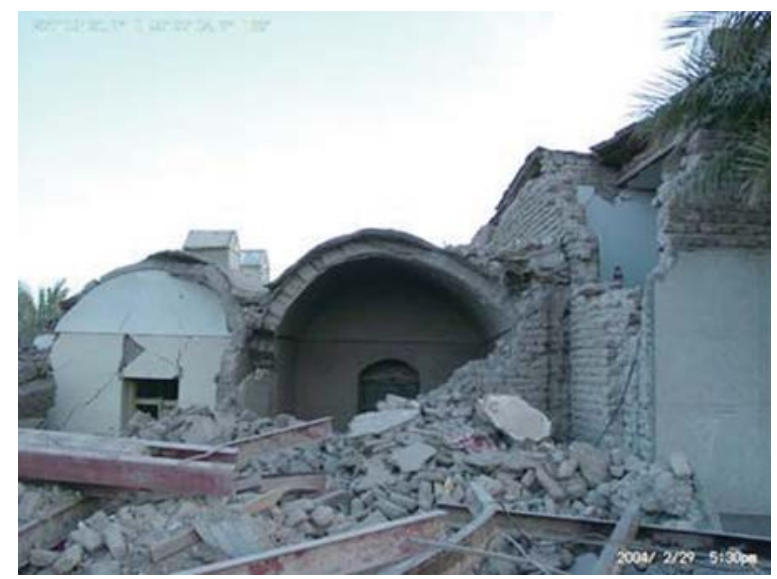

(a) Bam Earthquake, Iran (2003)

\section{(2) Simulation results}

For the flat roof models, the above collapse mechanism is confirmed by the simulation. For example, Flat20N in the case of LTV collapsed because the bearing wall fractured, but Flat $20 \mathrm{~N}$ in the case of TLV did not collapse because the bearing wall did not. Moreover, by increasing the thickness of the bearing wall of Flat20N, structural failure of Flat40N was avoided even though the nonbearing wall was the same.

For the vault roof models, thick bearing walls and wooden columns and beams had little effect. They only delayed the failure, and collapse of the roof could not be avoided. This is because the roof of the analyzed model itself was weak. The roof requires minimum levels of strength and integrity before reinforcements of bearing walls are effective.

It is noted that the comparison between the analytical results for flat and vaulted roof models does not indicate that the vaulted roof model is far more vulnerable to earthquakes. The analyzed flat roof model has much lighter roofs made only by wooden beams, but in reality, mud and trees branches are used to cover flat roofs depending on the area, and this makes the roof heavier and more vulnerable. Moreover, the vulnerability of the analyzed vault roof models changes depending on the roof thickness, so we cannot simply discuss the superiority of the flat and vaulted roof models through these simulation results.

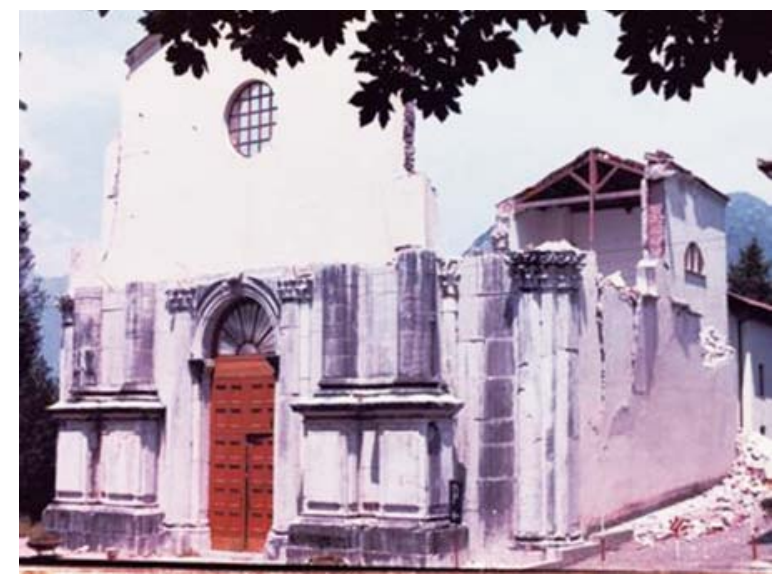

(b) Friuli Earthquake, Italy (1976)

Photo 1 Buildings damaged by earthquakes 


\subsection{Scattering of bricks after earthquakes}

(1) Flat roof models

The areas of scattered fallen bricks are compared. Overhead views from the basement of flat roof models are shown in Figs. 34 and 35.

In the case of LTV, Flat20W was severely damaged, and the bricks in the nonbearing walls were mainly scattered around these walls (Fig. 34 (a) ). In the case of TLV, Flat20W and Flat20N collapsed, and the area of scattered bricks for Flat20W was larger than that for Flat20N owing to the weakness of the mortar. It can be seen that the mortar strength affects not only the failure propagation process but also the area of scattering. Walls connected with weaker mortar tend to vibrate more greatly, and this may increase the area of scattered fallen bricks. The effect of the direction of the input ground motion is clear from a comparison of Figs. 34 and 35, since the flat roof models are damaged mainly by the earthquake ground motion.

\section{(2) Vault roof models}

Overhead views from the basement of the vault roof models are shown in Figs. 36 and 37. No effect of the direction of the input ground motion is seen in the comparison of Figs. 36 and 37 because the vault roof models collapsed owing to the weight imbalance induced by small deformation due to the initial earthquake ground motion.

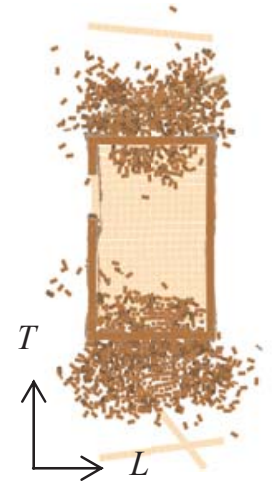

(a) Flat20W

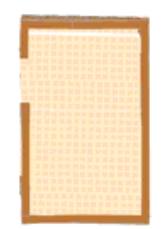

(b) Flat $20 \mathrm{~N}$

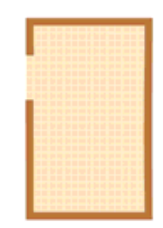

(c) Flat20S

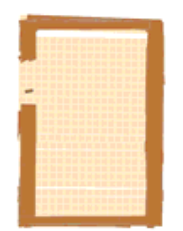

(d) Flat40N

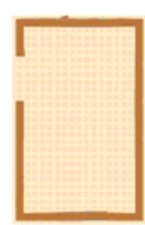

(e) Flat20R

Fig. 34 View from the basement of flat roof models, TLV

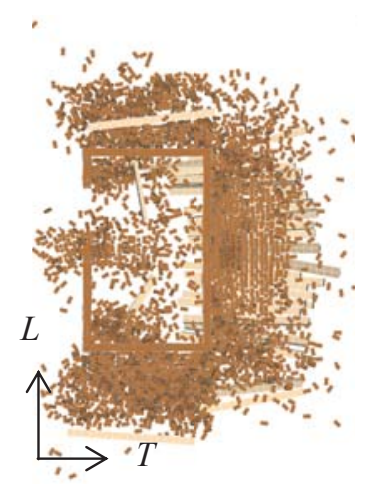

(a) Flat20W

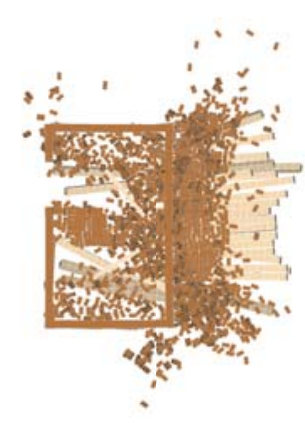

(b) Flat $20 \mathrm{~N}$

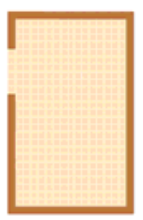

(c) Flat20S

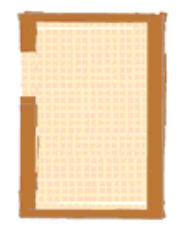

(d) Flat $40 \mathrm{~N}$

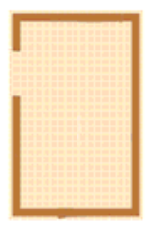

(e) Flat20R

Fig. 35 View from the basement of flat roof models, LTV 


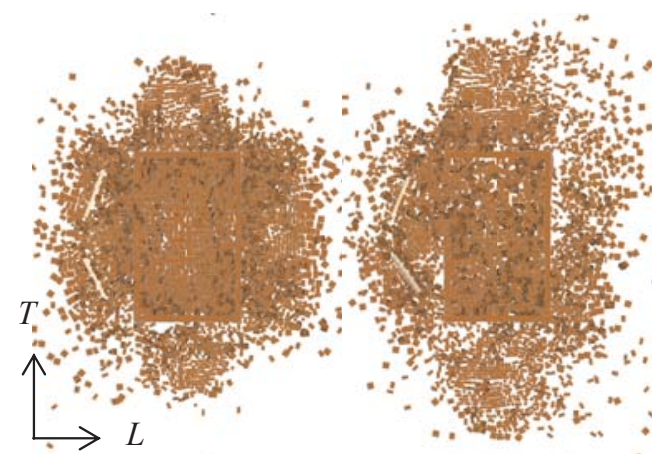

(a) Vault20W

(b) Vault $20 \mathrm{~N}$

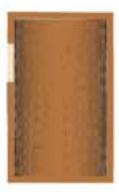

(c) Vault20S

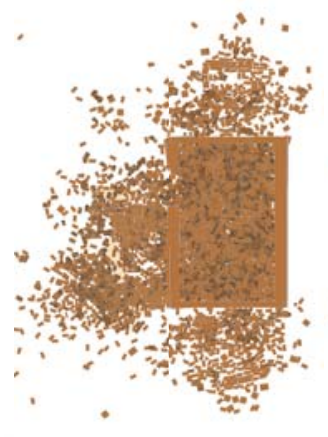

(d) Vault40N

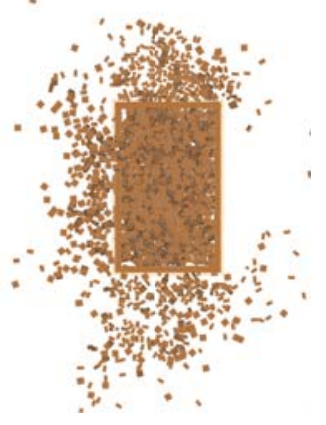

(e) Vault20R

Fig. 36 View from the basement of vault roof models, TLV

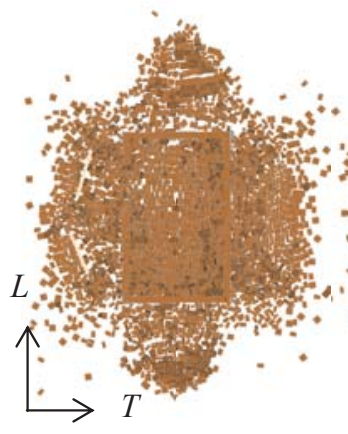

(a) Vault20W

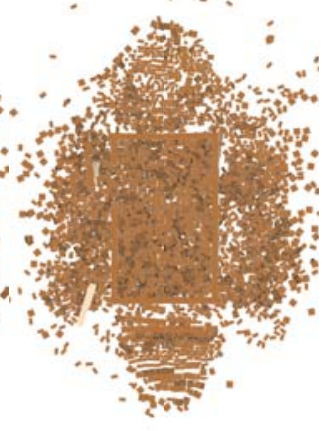

(b) Vault20N

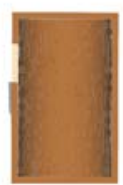

(c) Vault20S

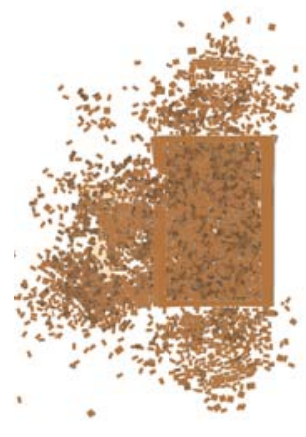

(d) Vault40N

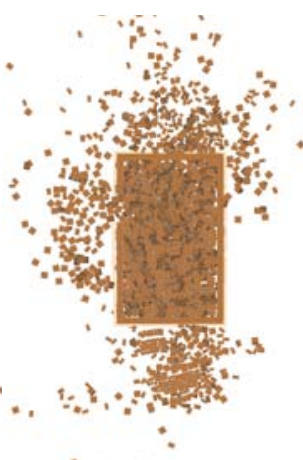

(e) Vault20R

Fig. 37 View from the basement of vault roof models, LTV

\section{Conclusions}

In this paper, failure propagation of masonry buildings during earthquakes is simulated using a refined DEM that can simulate three-dimensional elastic, failure, and collapse behaviors of structures. The seismic behaviors of models with a flat roof or vault roof are simulated and their failure mechanisms are discussed. In addition, the influence of the direction of the input ground motion on the failure propagation is investigated. Moreover, the effectiveness of three reinforcement measures was compared. One measure is increasing the mortar strength, the second is increasing the thickness of the bearing walls, and the third is introducing wooden columns and beams, which have higher tensile strength than the bricks.

Even though the simulation is limited to one set of earthquake records, the following findings are obtained through the simulations.

The stability of the roof of the flat roof models is dependent on the out-of-plane deformation of the bearing walls. Therefore, if the out-of-plane deformation of the bearing walls is small, collapse of the roof can be avoided. Therefore, a reinforcement that reduces out-of-plane deformation is effective. Increasing the thickness of the bearing walls and introducing wooden columns and beams are only partial reinforcements, but both are effective since they reduce outof-plane deformation. Increasing the mortar strength is the most effective approach since it increases the whole structural strength and reduces deformation on the whole. It is also found that the failure propagation of the flat roof models is dependent on the directions of the input ground motion since the out-of-plane deformation of the bearing walls depends on the characteristics of the ground motion.

For the vault roof models, the collapse of the roof is induced by its heavy weight and instability triggered by movement due to ground motion. Increasing the mortar strength is the most effective approach since it directly increases the strength of the roof. Increasing the thickness of the bearing walls and introducing wooden columns and beams are effective in reducing the instability of the roof since they reduce the out- 
of-plane deformation of the bearing walls supporting the roof. However, since these measures do not increase the strength of the roof, the roof collapses even though the bearing walls remain.

It is found that the roof needs minimum levels of strength and integrity before the reinforcement of bearing walls can become effective. If the roof has the minimum strength and integrity, the stability of the roof depends on the two bearing walls and failure of the roof is avoided if the bearing walls are supported somehow regardless of damage to nonbearing walls. Increasing the thickness of the bearing walls and introducing wooden beams and columns are both effective in reducing the out-of-plane deformation of the bearing walls. Increasing the mortar strength is the most effective approach since it increases the whole structural integrity including the walls and the roof.

In a future study, we would like to develop a code for evaluating the failure of the brick itself as well as an appropriate damping model.

\section{ACKNOWLEDGEMENTS}

This work was supported by a Grant-in-Aid for the Global COE Program "Global COE for Education, Research and Development of Strategy for Disaster Mitigation of Cultural Heritage and Historic Cities (Ritsumeikan University) " from the Ministry of Education, Culture, Sports, Science and Technology of Japan.

\section{REFERENCES}

[1] Giardini D, Gruenthai G, Shedlock K, Zhang P. The GSHAP Global Seismic Hazard Map. In: Lee WH-K, Kanamori H, Jennings PC, Kisslinger C, editors. International Handbook of Earthquake and Engineering Seismology. London UK: Academic Press, 1233-1239 vol. 81B, 2003.

[2] Coburn A, Spence R. Earthquake Protection. 2nd ed. Chichester: John Wiley and Sons, 2002.

[3] Grunthal, G. (ed.) European Macroseismic Scale 1998 (EMS-98). Cahiers du Centre Européen de Géodynamique et de Séismologie 15. Centre Européen de Géodynamique et de Séismologie,
Luxembourg, 1998.

[4] Furukawa A, Kiyono, J, Toki, K. Proposal of a Numerical Simulation Method for Elastic, Failure and Collapse Behaviors of Structures and its Application to Seismic Response Analysis of Masonry Walls. Journal of Disaster Research, Vol. 6, No. 1, 2011 (to be published).

[5] Zienkiewicz, OC, Taylor, RL. The Finite Element Method. 5th ed. Oxford, UK: Butterworth Heinemann vol. 1, 2, 3, 2000.

[6] Ghannad MA, Bakhshi A, Mousavi Eshkiki SE, Khosravifar A, Bozorgnia Y, Taheri Behbahani AA. A study on seismic vulnerability of rural houses in Iran. Proceedings of the First European Conference on Earthquake Engineering and Seismology, paper no. 680, 2006.

[7] Cao Z, Watanabe H. Earthquake response prediction and retrofitting techniques of adobe structures. Proceedings of the $13^{\text {th }}$ World Conference on Earthquake Engineering, paper no. 2594, 2004.

[8] Gambarotta, L., Lagomarsino, S. Damage Models for the Seismic Response of Brick Masonry Shear Walls. Part I: The Mortar Joint Model and its Applications. Earthquake Engineering and Structural Dynamics, Vol. 26, 423-429, 1997.

[9] Lourenco PB, Pots JG. Multisurface Interface Model for Analysis of Masonry Structures. Journal of Engineering Mechanics, 123:660-668, 1997.

[10] Cundall PA, Strack ODL. A Discrete Numerical Model for Granular Assemblies. Geotechnique, 29:47-65, 1979.

[11] Shi GH. Block System Modeling by Discontinuous Deformation Analysis. Southampton, UK: Computational Mechanics Publications, 1993.

[12] Kawai T. New Element Models in Discrete Structural Analysis. Journal of the Society of Naval Architects of Japan, 141:187-193, 1977.

[13] Alexandris A, Protopapa E, Psycharis I. Collapse mechanisms of masonry buildings derived by the distinct element method. Proceedings of the $13^{\text {th }}$ World Conference on Earthquake Engineering, paper no. 548, 2004.

[14] Bakhshi A, Bozorgnia Y, Ghannad MA, Khosravifar A, Eshkiki EM, Rofooei FR, Behbahani AT. Seismic vulnerability of traditional houses in Iran. Seismo Adobe 2005 Seminar. Available 
at: http://www.3ei.org/images/peru05paper.pdf. Accessed January 28, 2010.

[15] Lourenco PB. Analysis of Masonry Structures with Interface Elements, Theory and Applications. Delft University of Technology, Faculty of Civil Engineering, TU-DELFT report no. 0321-22-0-01, 1994.

[16] Courant RL. Variational Methods for the Solution of Problems of Equilibrium and Vibration. Bulletin of the American Mathematical Society, 49:1-23, 1943.

[17] Kiyono J, Kalantari A. Collapse Mechanism of
Adobe and Masonry Structures during the 2003 Iran Bam Earthquake. Bulletin of Earthquake Research Institute, University of Tokyo, 79:157161, 2004.

[18] Marzahn G. The Shear Strength of Dry-Stacked Masonry Walls. Leipzig Annual Civil Engineering Report (LACER) No. 3. Germany: University of Leipzig, 1998.

[19] BHRC. The Very Urgent Preliminary Report on Bam Earthquake of Dec 26, 2003. http://www. bhrc.gov.ir, 2003. 